\title{
Using a nested single-model large ensemble to assess the internal variability of the North Atlantic Oscillation and its climatic implications for central Europe
}

\author{
Andrea Böhnisch ${ }^{1}$, Ralf Ludwig ${ }^{1}$, and Martin Leduc ${ }^{2,3}$ \\ ${ }^{1}$ Department of Geography, Ludwig-Maximilians-Universität München, Munich, Germany \\ ${ }^{2}$ Ouranos, Montréal, Québec, Canada \\ ${ }^{3}$ Centre ESCER, Université du Québec à Montréal, Montréal, Québec, Canada \\ Correspondence: Andrea Böhnisch (a.boehnisch@1mu.de)
}

Received: 25 September 2019 - Discussion started: 2 October 2019

Revised: 11 May 2020 - Accepted: 4 June 2020 - Published: 23 July 2020

\begin{abstract}
Central European weather and climate are closely related to atmospheric mass advection triggered by the North Atlantic Oscillation (NAO), which is a relevant index for quantifying internal climate variability on multi-annual timescales. It remains unclear, however, how large-scale circulation variability affects local climate characteristics when downscaled using a regional climate model. In this study, 50 members of a single-model initial-condition large ensemble (LE) of a nested regional climate model are analyzed for a NAO-climate relationship. The overall goal of the study is to assess whether the range of NAO internal variability is represented consistently between the driving global climate model (GCM; the Canadian Earth System Model version 2 CanESM2) and the nested regional climate model (RCM; the Canadian Regional Climate Model version 5 CRCM5). Responses of mean surface air temperature and total precipitation to changes in the NAO index value are examined in a central European domain in both CanESM2-LE and CRCM5-LE via Pearson correlation coefficients and the change per unit index change for historical (1981-2010) and future (2070-2099) winters. Results show that statistically robust NAO patterns are found in the CanESM2-LE under current forcing conditions. NAO flow pattern reproductions in the CanESM2-LE trigger responses in the high-resolution CRCM5-LE that are comparable to reanalysis data. NAO-response relationships weaken in the future period, but their intermember spread shows no significant change. The results stress the value of single-model ensembles for the evaluation of internal variability by pointing out the large differences of NAO-response relationships among individual members. They also strengthen the validity of the nested ensemble for further impact modeling using RCM data only, since important large-scale teleconnections present in the driving data propagate properly to the fine-scale dynamics in the RCM.
\end{abstract}

\section{Introduction}

One of the major sources of uncertainty regarding shortterm future climate projections is internal climate variability, while model climate response and greenhouse gas concentration scenarios become more important sources of uncertainty on a longer-term time horizon (Hawkins and Sutton, 2009, 2011). The term "internal variability" denotes climate variability which is not forced by external processes (either anthropogenic or natural) but arises from the chaotic properties of the climate system itself (Leduc et al., 2019; Deser et al., 2012), i.e., from varying sequences of weather events under identical external forcings. These sequences of weather events may be altered by global atmospheric modes of variability through the linking between large-scale circulation and local weather characteristics (like surface air temperature and precipitation). Such large-scale atmospheric modes can thereby establish periods of discernible states on multiannual timescales. 
Among these modes, the North Atlantic Oscillation (NAO) is particularly important for Northern Hemisphere climate. Its two states, positive and negative, are evoked by planetary wave breaking in the polar front, leading to antagonistic pressure behavior of two centers over the North Atlantic: one located within the subtropical high-pressure belt ("Azores High", $\mathrm{AH}$ ) and the second in subpolar regions ("Icelandic Low", IL) (Benedict et al., 2004). The resulting pressure gradient, which is stronger during positive and weaker during negative phases, affects large-scale extratropical circulation, especially the strength and position of midlatitude westerly winds connected to the jet stream, and air mass advection during boreal winter (Deser et al., 2017; Hurrell and Deser, 2010). Compared with neutral conditions, the positive NAO state leads to warmer and moister winters in northern Europe but cooler and drier conditions in the south, and vice versa in the negative state (e.g., Hurrell and Deser, 2010; Pokorná and Huth, 2015; Woollings et al., 2015).

The NAO is commonly quantified with an index that makes use of the air pressure or geopotential height gradient between AH and IL. The index may be calculated as a normalized difference of station measurements, spatially averaged values of preset regions, or the region of highest variance is obtained by principal component analysis (PCA) (Pokorná and Huth, 2015; Hurrell and Deser, 2010; Stephenson et al., 2006; Hurrell, 1995; Rogers, 1984). Each method has its advantages and limitations. For example, stationbased or fixed-in-space indices do not reproduce shifting NAO patterns and may be affected by microclimatic noise and other teleconnection patterns (Hurrell and Deser, 2010; Osborn, 2004). Indices based on PCA on the other hand are dependent on the chosen data domain for calculation and on the data set itself (Osborn, 2004). The different approaches, however, lead to highly similar index time series (see, e.g., Pokorná and Huth, 2015, for a detailed survey of various approaches).

While the typical NAO pattern and its impacts are usually correctly reproduced in global climate models (GCMs) (Stephenson et al., 2006; Ulbrich and Christoph, 1999; Reintges et al., 2017), its fidelity in a future climate remains uncertain: the NAO is found as intensifying but also counteracting global warming in the Northern Hemisphere ("global warming hiatus"; Iles and Hegerl, 2017; Deser et al., 2017; Delworth et al., 2016). Similarly, the findings regarding the prevalence of future positive or negative states lack unity. Some analyses of CMIP5 models, for example, suggest more positive phases under rising greenhouse gas concentrations until 2100 (e.g., Kirtman et al., 2013; Christensen et al., 2013), others favor an increase of negative phases (Cattiaux et al., 2013).

In most of these studies, it was common to rely on one simulation per model and estimate the model's performance regarding the NAO by this single run. This approach allows for comparing different models (and observations). However, it is not possible to robustly evaluate the range of NAO index values and evolution in a projected future climate, or whether the chosen simulation is a good representation of how this model simulates the phenomenon in question (Leduc et al., 2019). Relying on single realizations possibly deteriorates the assessment of a given model, as single realizations may vary considerably among themselves due to internal variability (and also deviate from the climate evolution observed in reality). One way to sample realizations is to perturb the initial conditions of the model, leading to multiple simulations with identical external forcing which only differ due to internal variability. Examples for recent GCM initial-condition large ensembles of transient simulations are the 100-member Max Planck Institute Grand Ensemble (MPI-GE; Maher et al., 2019), the 50-member Canadian Earth System Model Large Ensemble (CanESM2-LE, e.g., Kirchmeier-Young et al., 2017; Fyfe et al., 2017) or the 40-member Community Earth System Modelling Large Ensemble (CESM-LE Kay et al., 2015) which were, among others, used for various analyses of internal variability or extreme events. Such initial-condition ensembles also allow a more robust distribution of atmospheric modes to be sampled, as was done, e.g., for El Niño-Southern Oscillation (ENSO) in Maher et al. (2018). That is why the present study is investigating the NAO pattern in a single-model large ensemble of a GCM.

However, when interested in NAO impacts on a regional scale, like central Europe, the GCM is not sufficient for finescale responses. Due to their coarse spatial resolution, GCMs poorly resolve land-water contrasts and topographic characteristics which may be highly relevant in climate impact studies over heterogeneous landscapes (Leduc et al., 2019). Thus, dynamical downscaling of the GCM members using a regional climate model (RCM) is advised (Leduc et al., 2019). The downscaling of a GCM single-model large ensemble, CanESM2-LE, was performed within the Climate Change and Hydrological Extremes project (ClimEx; http: //www.climex-project.org/, last access: 3 July 2020; Leduc et al., 2019).

Examples of analyses on the separation of the forced signal from internal variability within a 16-member singlemodel initial-condition GCM-RCM ensemble of EC-Earth and RACMO2 were performed by Aalbers et al. (2018) for various extreme precipitation indices.

Combining the driving GCM and nested RCM (i.e., driven by lateral boundary conditions of the GCM) large ensembles (LEs) allows for analyzing the spread of NAO states and responses within one model chain. In doing so, it is possible to establish the range of internal variability of the NAO and find robust NAO and response patterns by significantly reducing uncertainty associated with internal variability in the ensemble.

The present study targets the research question of how global circulation variability, in this case the NAO teleconnection, affects local climate characteristics when downscaled using an RCM. It specifically aims at evaluating 
whether the range of internal variability is represented consistently between the driving GCM-LE and the driven highresolution RCM-LE. The latter may be important for impact modelers who work with RCM data on internal variability without taking the driving GCM into account.

To answer these research questions, this study focuses on four topics and related key questions:

a. Regarding the general performance of the model chain, can the driving GCM resolve the NAO correctly and are climatic implications for central Europe reproduced?

b. In terms of the nesting approach, does the RCM correctly incorporate the NAO pattern present in the driving data and produce realistic response patterns?

c. For internal variability, what is the range of possible NAO patterns and responses, expressed by the intermember spread among the 50 members of the GCM-LE and the RCM-LE?

d. With climate change, how do topics (a)-(c) change in transient climate simulations that extend until 2099 using an RCP8.5 emissions scenario?

\section{Data and methodology}

\subsection{Data}

Data from three different sources are employed in this study (Table 1). The major source is the RCM-LE data set of the ClimEx project which is described in detail in Leduc et al. (2019). The ClimEx project is conducted in a Québec-Bavarian cooperation and targets issues of hydrological extreme events in the time horizon of 1950-2099, using a nested high-resolution 50-member single-model initialcondition large ensemble with an RCP8.5 emissions scenario from 2006 onwards (Leduc et al., 2019). Five members of CanESM2-LE (2.8 ${ }^{\circ}$ spatial resolution; Fyfe et al., 2017) with different ocean initial conditions were slightly perturbed in 1950 , leading to 10 members per ocean family. The members are assumed to become independent about 5 years after their initialization in 1950 (spin-up period) (Leduc et al., 2019).

Regarding the atmospheric circulation, Fig. 1 shows that, due to the chaotic nature of the atmospheric system, the daily NAO index seems to lose dependence on the initial conditions within the course of 1 month after initialization (see Leduc et al., 2019, for a similar presentation of member independence).

As described in Leduc et al. (2019), the 50 CanESM2 members were dynamically downscaled using the Canadian Regional Climate Model version 5 (CRCM5 Large Ensemble, $0.11^{\circ}$ spatial resolution) over two domains covering Europe and northeastern North America, each sized $280 \times$ 280 grid cells on a rotated grid. Large-scale spectral nudging

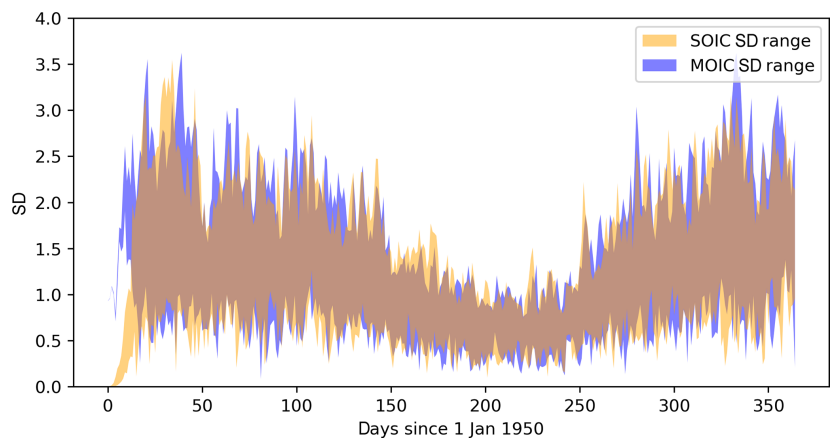

Figure 1. Inter-member standard deviation of a daily NAO index in CanESM2-LE starting on 1 January 1950 as a function of time. The inter-member standard deviation (SD) is derived from 10 groups of five members with the same ocean initial conditions (SOICs) and 10 groups of five members with mixed ocean initial conditions (MOICs, following an approach in Leduc et al., 2019).

of the horizontal wind field was applied during the nesting process (Leduc et al., 2019). This single-RCM 50-member ensemble allows for internal variability and extreme events to be detected in high spatial and temporal resolution within a total of 7500 modeled years (Leduc et al., 2019).

Comparing the internal variability of the CRCM5 members with the inter-member spread of a subset of the multi-model EURO-CORDEX (Coordinated Regional Climate Downscaling Experiment) ensemble regarding regionally integrated European winter temperature and precipitation, von Trentini et al. (2019) showed that both ensemble spreads are of comparable magnitude. The CORDEX ensemble consists of several GCM-RCM combinations set up in a coordinated modeling framework and aims at evaluating uncertainty due to model configuration (Giorgi et al., 2009). The comparison of the single-model and multi-model spreads suggests that a large fraction of the CORDEX ensemble spread regarding temperature and precipitation can be explained by internal variability, despite the fact that it was not explicitly sampled within the CORDEX framework (where most models provided a single simulation; von Trentini et al., 2019). At smaller regional scales, however, singlemodel and multi-model spreads may show considerable and in parts temporally changing differences which may partly be induced by model response uncertainties (von Trentini et al., 2019).

In the present study, model data are compared with the ERA-Interim (ERA-I) reanalysis data set of the European Centre for Medium-Range Weather Forecasts (Dee et al., 2011, ECMWF). Additionally, a CRCM5 run driven by ERA-I is used to evaluate CRCM5 under "perfect" (as far as ERA-I can be assumed to represent reality) lateral boundary conditions, i.e., without the potential CanESM2 data input error.

The relevant variables for this study are 
Table 1. Overview of used data sets, their spatial resolution, the number of members and the employed variables.

\begin{tabular}{llrrll}
\hline Data name & Model type & Spatial resolution & Members & Model output variable names & Institution \\
\hline ERA-I & Reanalysis & $0.75^{\circ} \times 0.75^{\circ}$ & 1 & $\mathrm{msl}(\mathrm{Pa}), \mathrm{t} 2 \mathrm{~m}(\mathrm{~K}), \mathrm{tp}(\mathrm{m})$ & ECMWF \\
CRCM5/ERA-I & RCM & $0.11^{\circ} \times 0.11^{\circ}$ & 1 & $\mathrm{psl}(\mathrm{Pa}), \operatorname{tas}(\mathrm{K}), \mathrm{pr}\left(\mathrm{kg} \mathrm{m}^{-2} \mathrm{~s}^{-1}\right)$ & $\mathrm{Ouranos}^{-1}$ \\
CanESM2-LE & GCM & $2.8^{\circ} \times 2.8^{\circ}$ & 50 & $\mathrm{psl}(\mathrm{Pa}), \operatorname{tas}(\mathrm{K}), \mathrm{pr}\left(\mathrm{kg} \mathrm{m}^{-2} \mathrm{~s}^{-1}\right)$ & $\mathrm{CCCma}^{*}$ \\
CRCM5-LE & RCM & $0.11^{\circ} \times 0.11^{\circ}$ & 50 & $\mathrm{psl}(\mathrm{Pa}), \operatorname{tas}\left({ }^{\circ} \mathrm{C}\right), \mathrm{pr}(\mathrm{mm})$ & Ouranos \\
\hline
\end{tabular}

* CCCma - Canadian Centre for Climate Modelling and Analysis.

- (mean) sea level air pressure (referred to as "SLP", converted to $\mathrm{hPa}$;

- near-surface air temperature (referred to as "nSAT", converted to $\mathrm{K}$ ); and

- total precipitation including liquid and solid precipitation from all types of clouds (referred to as "PR", converted to $\mathrm{mm}$ ).

ERA-I variables t2m, tp and msl (Table 1) are chosen as they are assumed to most accurately represent the GCM and RCM variables. As the variables derived from the three data sources are available at different temporal resolutions (3hourly for tas and psl in RCM, hourly for pr in RCM, daily for psl, pr and tas in GCM, 6-hourly for ERA-I t2m and msl analysis, and 12-hourly for ERA-I tp forecast data), they are all aggregated to daily values first.

In the Appendix, Fig. A1 shows that CRCM5 tends to underestimate (overestimate) mean winter nSAT mean in the northern (southern) part of the domain, regardless of the driving data (Fig. A1a for ERA-I and Fig. A1c for CanESM2), whereas winter PR sums are overestimated in nearly the entire domain, with strongest values in the southeastern part (Fig. A1d and f). Displaying the opposite bias of CRCM5, CanESM2 overestimates (underestimates) mean winter nSAT in the northern (southern) part of the domain (Fig. A1b), whereas winter PR sum is underestimated in the eastern half of the domain and overestimated on the western side of the Alps (Fig. A1e). As this study will focus on responses of nSAT and PR induced by the NAO (see Sect. 2.2.4), aside from regions with particularly high PR sum values, it is found that such NAO responses are generally insensitive to these biases.

Commonly, NAO impact studies focus on seasonally aggregated values of the analyzed variables or extreme events (e.g., Stephenson et al., 2006). Yet the NAO, which accounts for variations in the mean zonal atmospheric flow towards Europe, can be assumed to influence not only winter mean values but also their interannual variability. So, in addition to analyses of winter mean temperature (nSAT mean) and precipitation sums (PR sum), selected analyses are also performed on winter mean monthly standard deviations of daily mean temperature (nSAT SD) as a measure of temperature variability.

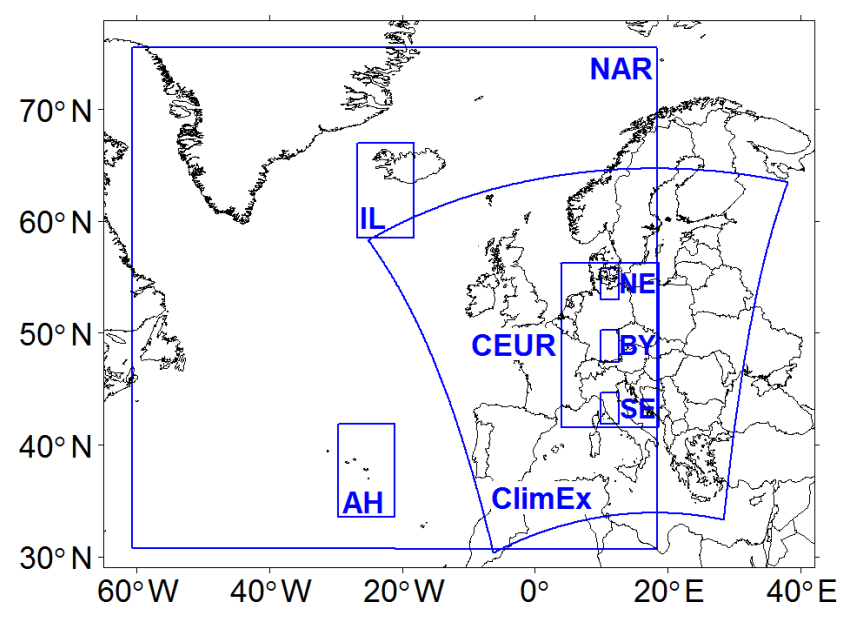

Figure 2. Regions of interest. Abbreviations and domain sizes in terms of GCM grid cells $\left(2.8^{\circ}\right)$ are as follows: AH - Azores High $(3 \times 3)$; IL - Icelandic Low $(3 \times 3)$; NAR - large-scale North Atlantic region $(28 \times 16)$; CEUR - central Europe $(5 \times 5)$; NE - northern Europe (1); BY - Bavaria (1); SE - southern Europe (1); ClimEx domain used in ClimEx project (extent approximately $22 \times 12$ after resampling to GCM grid).

\subsection{Methodology}

\subsubsection{Regions of interest and time horizon selection}

Analyses are performed on time series of spatially averaged information (nSAT mean, PR sum for response variables and SLP for index calculation) as well as on spatially explicit data (nSAT mean, nSAT SD, PR sum). All data are provided as NetCDF files, and most pre-processing is performed using the Climate Data Operators (CDOs) of the Max Planck Institute for Meteorology (Schulzweida, 2017).

The regions of interest and their names used in this study are displayed in Fig. 2. The formation of the NAO over the North Atlantic (NAR, AH, IL regions) is analyzed in the ERA-I and CanESM2-LE data, while responses over central Europe (CEUR, NE, BY, SE regions) are evaluated in ERA-I, CRCM5/ERA-I, CRCM5-LE and CanESM2-LE data.

$\mathrm{AH}$ and IL regions are centered over Ponta Delgada (Azores) and Reykjavik (Iceland), two commonly used stations for NAO index calculations. To avoid microclimatic impacts and sampling uncertainties of a single grid cell and 
to account for moving SLP centers (see, e.g., Moore et al., 2013), both NAO core regions are extended to $3 \times 3 \mathrm{GCM}$ grid cell matrices. In preliminary analyses conducted for the present study, the NAO index has proven to be very robust towards the exact shape of the core regions.

The central European domain (CEUR) is defined in CanESM2-LE by selecting a $5 \times 5$ GCM grid cell matrix centered over Munich (Germany). This CEUR domain extends from Denmark in the north to central Italy in the south and from Poland to France in the east-west direction. The corresponding CEUR region within the ClimEx European domain is used to quantify the impacts of the NAO in the CRCM5LE data. It lies downstream of the westerly flows initiated by the NAO, so the following analyses set a special focus on the incorporation of large-scale inflow from the western side into the nested RCM.

As the responses to the NAO are expected to vary over the CEUR domain, it seems favorable to analyze spatial structures explicitly in addition to analyses of time series over several subset regions. These subset regions (see, e.g., Déqué et al., 2007) denote small-scale sample areas inside the CEUR domain, sized one GCM grid cell each, with expected typical "northern European" (NE) and "southern European" (SE) NAO responses for a more detailed statistical analysis. A third GCM grid cell is chosen to represent the transition zone between NE and SE. Coincidentally, it closely represents the region of Bavaria, which is why the name "BY" is assigned to it. ERA-I and RCM data $(3 \times 4$ and $26 \times 26$ grid cells, respectively) are spatially aggregated to GCM resolution for this part of the analysis.

This study focuses on interannual analyses which are conducted for two time horizons covering 30 years each. The historical (hist; 1981-2010) period is used to establish reference statistics in the ERA-I data and the ERA-I-driven CRCM5 run which are then evaluated in the GCM-LE and the RCMLE. Links and relationships established for the historical period are also investigated in a far future horizon (fut; 20702099).

The chosen period length is assumed to include major fluctuations, like internal climate variations or several solar cycles, which might affect NAO phases (Andrews et al., 2015). Thus, their influence can be assumed to be represented by the sampled NAO time series. Relationships between the NAO and response variables most probably vary on different timescales (Hurrell and Deser, 2010; Woollings et al., 2015; $\mathrm{Xu}$ et al., 2016; Hurrell and Van Loon, 1997). However, as 30 -year periods are not long enough for analyses of multidecadal (> 30-year) NAO-response variability (Woollings et al., 2015), stationarity in NAO-impact relationships is assumed for simplicity reasons.

Since the NAO is known to be strongest in winter (Hurrell and Deser, 2010) and the connection between stationbased indices and NAO responses tends to be best in winter (see Pokorná and Huth, 2015, for DJF months), analyses are performed for this season only. Preliminary tests within this study have shown that correlations and links between the NAO index and the climate variables are more distinct from noise, if March is included as well. That is why an extended winter season is used here (DJFM; see also Iles and Hegerl, 2017; Hurrell, 1995; Osborn, 2004).

All data (spatially explicit and subset time series) are aggregated to the seasonal timescale for further use (winter means for nSAT and winter sums for PR).

\subsubsection{Deriving a NAO index}

The NAO index is derived from ERA-I and CanESM2-LE data, resulting in 1 ERA-I and 50 GCM realizations. As the CRCM5 ClimEx domain does not cover the AH and IL regions (see Fig. 2), the index is not derived from this data source. The NAO is quantified in this study with an index which is closest to a station based or zonally averaged index. It therefore directly represents the winter SLP gradient over the North Atlantic.

The time series of AH and IL originate from the temporally shortened and spatially averaged SLP time series of both grid cell matrices. Daily SLP values are averaged to monthly means (Cropper et al., 2015) and scaled to obtain mean $\mu=0$ and standard deviation of $1 \sigma$, as outlined in Osborn (2004) and Hurrell and Van Loon (1997), by subtracting the 1981-2010 seasonal mean (overbar) and dividing by the 1981-2010 seasonal standard deviation $\left(s_{\mathrm{IL}}, s_{\mathrm{AH}}\right)$ :

$\mathrm{NAO}$ index $=\frac{\mathrm{AH}-\overline{\mathrm{AH}}}{s_{\mathrm{AH}}}-\frac{\mathrm{IL}-\overline{\mathrm{IL}}}{s_{\mathrm{IL}}}$.

Monthly indices are next averaged to DJFM means. This approach is similar to Woollings et al. (2015) and Jones et al. (2013).

The ERA-I NAO index calculated this way shows high agreement with often-cited NAO indices like the time series of Hurrell (Pearson correlation of $r=0.95$ with ERA-I NAO index; index available at https://climatedataguide.ucar.edu/climate-data/ hurrell-north-atlantic-oscillation-nao-index-station-based, last access: 3 July 2020). For further analyses, it will therefore serve as a reference.

To compare future with historical index values, the future time series of AH and IL are standardized with the historical SLP standard deviations (see also Ulbrich and Christoph, 1999; Hansen et al., 2017) and mean values. The standardization of each GCM member is carried out individually.

\subsubsection{Evaluation of the large-scale SLP pattern in RCM data}

To estimate whether the NAO may be seen as being correctly represented in the nested RCM data, the reproduction of interannual SLP pattern variations in the CRCM5 data is verified. Therefore, monthly mean SLP data of CRCM5 (both driving data sets) and ERA-I are linearly interpolated 
to GCM resolution over the ClimEx domain. During interpolation, small scales are automatically filtered such that the remaining large scales of driving data and RCM data may be compared. As a next step, a root mean square difference (RMSD) of the difference time series between monthly mean driving and RCM data over the hist and fut time periods is obtained across all members and winter months:

$$
\begin{aligned}
& \operatorname{RMSD}(i, j)=\left\langle\left\langle\frac{\sqrt{\left\langle D_{\mathrm{m}}(i, j, t, n)^{2}\right\rangle_{t}}}{\sqrt{\operatorname{VarDrive}_{\mathrm{m}}(i, j, n)}}\right\rangle_{n}\right\rangle_{m} \\
& \operatorname{VarDrive}_{\mathrm{m}}(i, j, n)=\left\langle\left(\text { Drive }_{\mathrm{m}}(i, j, t, n)\right.\right. \\
& \left.\left.-\left\langle\operatorname{Drive}_{\mathrm{m}}(i, j, t, n)\right\rangle_{t}\right)^{2}\right\rangle_{t},
\end{aligned}
$$

where $\langle\cdot\rangle$ is the averaging operator over a given index, $D_{\mathrm{m}}$ is the difference between monthly mean driving data and RCM data; Drive ${ }_{m}$ is driving SLP data; VarDrive $_{m}$ is the variance of SLP driving data over the 30-year periods; $i, j$ are spatial grid coordinates, $m$ indicates months $12,1-3, n$ indicates ensemble members 1-50 for CanESM2 and member 1 for ERA-I, and $t$ indicates years in 1981-2010 and 2070-2099. The normalization by the square root of the temporal variance of the driving data provides a measure relative to the interannual variability of the SLP pattern in a given location.

\subsubsection{Climatic changes associated with NAO}

All data sources (Table 1) are used to obtain response patterns of the variables nSAT and PR. Climatic changes associated with the NAO are evaluated using Pearson correlation coefficients and a slope parameter obtained by linear regression.

ERA-I and CRCM5/ERA-I nSAT and PR data are correlated with the ERA-I index, CanESM2 and CRCM5 members are correlated with the CanESM2 index calculated for the corresponding member.

The correlation analysis assumes (symmetric) linear relationships between the NAO index and nSAT or PR. The associated response of the variables to NAO changes may then be quantified by a linear equation (Iles and Hegerl, 2017; Stephenson et al., 2006; Hurrell, 1995):

$Y=\alpha_{1} X+\alpha_{0}+\varepsilon_{Y}$,

with $Y$ being the (response) variable at a given grid cell that is partly explained by the NAO ( $X$, the predictor) and by any other influences $\left(\varepsilon_{Y}\right.$; Stephenson et al., 2006; von Storch and Zwiers, 2003). The coefficient $\alpha_{1}$ is estimated on each grid cell using ordinary least squares regression with the $R$ function $1 \mathrm{~m}$ (https://www.rdocumentation.org/, last access: 3 July 2020). It represents mean change in nSAT or PR that accompanies unit index change during the time period under consideration (Iles and Hegerl, 2017). The line offset $\alpha_{0}$ in Eq. (4) is equal to the long-term mean. The $\alpha_{1}$ coefficients may be computed with respect to normalized index series (von Storch and Zwiers, 2003), but in this study the nonnormalized index time series is preferred in order to take into account the member-specific index units. The NAOresponse relationship is analyzed individually for each GCM and RCM member (as is done, e.g., in Woollings et al., 2015).

\subsubsection{Addressing internal variability}

In this study, the GCM-RCM combination allows to set a focus on the internal variability of an RCM ensemble and the driving GCM ensemble. Climate modes tend to show high internal variability (see, e.g., Maher et al., 2018, for an analysis of ENSO internal variability in CMIP5 models and two single-model large ensembles). The present study targets the NAO-related internal variability within a single GCM-RCM combination.

In general, natural internal variability may be understood from different angles. When looking into single realizations of time series of a given variable, internal variability may be seen as represented by the oscillation around the long-term mean evolution, i.e., the residuals (Frankcombe et al., 2015; Hawkins and Sutton, 2009, 2011). In this case, the amplitude of internal variability is usually calculated as a time-invariant quantity for the period under consideration (Hawkins and Sutton, 2009, 2011).

Another way is investigating transient internal variability in initial-condition ensembles, e.g., in Maher et al. (2019). In this case, the ensemble establishes ranges of possible weather event sequences by superposing single realizations which are equally likely by construction of the ensemble.

In the present study, the latter approach is used within the 50-member CanESM2-LE and CRCM5-LE. This allows to sample internal variability at single points in time as the range of the members' values, i.e., across members (e.g., Maher et al., 2018). While internal variability is assumed to be stationary within both 30 -year periods for this study, the use of a LE allows to detect potential changes in internal variability between both analysis periods.

Internal variability is expressed as the across-member standard deviation, i.e., the inter-member spread of CanESM2-LE and CRCM5-LE (see also Leduc et al., 2019; Déqué et al., 2007; Aalbers et al., 2018) among the 30-year means, rather than computing a transient internal variability at each time step as was done, e.g., in Maher et al. (2019). Aggregations to ensemble means (like in Deser et al., 2017; Aalbers et al., 2018) of NAO responses are only performed for illustrating purposes in order to avoid masking model internal variability (Zwiers and von Storch, 2004).

\section{Results}

The result section is structured in two large parts: Sect. 3.1 deals with the representation of the NAO and climatic responses in the GCM and RCM, and Sect. 3.2 targets internal variability in the GCM and RCM. 


\subsection{NAO within the ClimEx data set}

Naturally, the first step when evaluating the NAO in a model ensemble is to analyze its representation and index distribution in the model data of interest.

\subsubsection{NAO index and SLP conditions}

CanESM2-LE produces NAO index values which follow a distribution comparable to the ERA-I data (similar to a normal distribution with $\mu=0, \sigma=1$; Fig. 3a), but the CanESM2-LE distribution appears smoother due to a larger sample size ( $n=1500$ for CanESM2-LE and $n=30$ for ERA-I). Maximum and minimum index values ( $x$ axis in Fig. 3a) of some of the 50 members exceed those of the ERAI realization; thus, ERA-I which serves as a reference realization lies well within the ensemble inter-member spread. The future NAO index shows a similar distribution of values but with slightly less positive and more negative values (red curve in Fig. 3a).

For the following analyses, independence of the 50 members is critical to interpreting the inter-member spread as a proxy for internal variability. In evaluating this, it is important to recall that the 50-member CanESM2-LE was constructed in two steps (Fyfe et al., 2017; Leduc et al., 2019). First, independent atmosphere-ocean states in 1850 were used to launch five historical simulations integrated forward until 1950. Second, in 1950, each of these five ensemble members was used to launch 10 individual simulations by applying a small perturbation to the atmosphere and integrated forward until 2099, thereby producing the 50-member large ensemble.

As a consequence, for this study, members between each of the five groups of 10 are expected to be independent. However, members within each group of 10 are highly correlated in 1950 and progressively increase their independence beyond their 1950 starting point. To evaluate whether the 10 members within each of the five groups have become sufficiently independent by the two 30-year periods of interest (1981-2010 and 2070-2099), correlations among member time series are applied to two groups following Leduc et al. (2019): (i) correlations among the 10 members from the same group (same ocean initial conditions, SOICs; $n=225$ cases, dotted lines in Fig. 3b) and (ii) correlations between each member and the 40 members from the four other groups (MOICs, $n=1000$ cases, solid lines in Fig. 3b).

These correlations approximately follow a normal distribution with $\mu=0$ and $\sigma=0.2$. There is a slight surmount of low positive correlations in the SOIC group compared with the MOIC group which is (not significantly) stronger in the fut time horizon (see red and black dotted lines in Fig. 3b). Although zero correlations do not necessarily imply independence, clear correlations among members would contradict the assumption of independence. In general, the members are thus not seen as being dependent.
As will be discussed below, the SLP pattern over the North Atlantic changes slightly in the future period. So the direct comparison between historical and future SOIC and MOIC correlations remains difficult. The members also show no systematic correlation with the ERA-I NAO index despite similar statistics (see also Fig. 9). Thus, the ERA-I and GCM indices can be seen as not dependent realizations drawn from the same distribution.

In order to further evaluate the NAO representation in CanESM2-LE, Fig. 4 presents the large-scale SLP patterns in the NAR region during neutral, positive and negative NAO conditions. Positive (negative) index years are chosen, if the respective index value exceeds $1(-1)$ as in Rogers (1984). The neutral conditions refer to the 30-year SLP average. Regions with strong sampling uncertainties, i.e., where the standard error is larger than the anomaly, are indicated with stippling in Fig. 4b, c, e and $\mathrm{f}$.

Under neutral NAO conditions, the North Atlantic region is characterized by a pressure dipole. This structure is intensified and tilted clockwise in the CanESM2-LE ensemble mean (Fig. 4d) compared with ERA-I (Fig. 4a). The mean SLP difference between the CanESM2-LE mean and ERA-I reaches up to $10 \mathrm{hPa}$ in both directions. SLP values are higher over Greenland and lower over the North Sea in CanESM2LE compared with ERA-I (Fig. 4a and d). Long-term neutral states of both driving data sources show robust signals in the entire NAR region (i.e., no stippling). This suggests that the different patterns in GCM and reference data are not singularly artifacts arising from different sample sizes but rather robust features.

The GCM multi-member composites of positive and negative phases show less pronounced SLP anomalies than the reference data (Fig. 4b, c, e and f). Transition regions between the $\mathrm{AH}$ and IL nodes are marked by high uncertainty in ERA-I, whereas the SLP anomalies at the NAO centers of action show less uncertainty. The GCM patterns are more robustly assessed (i.e., less prone to sampling uncertainty) as can be seen by the very small area with stippling in which the sign of the anomaly may not be assessed robustly in Fig. 4e and $\mathrm{f}$. So the difference between CanESM2-LE and ERA-I NAO anomalies may be due to the fact that ERA-I composites are derived from 3 negative and 4 positive years, whereas the GCM data provide 264 negative and 263 positive years during 1981-2010.

The difference between SLP anomalies in positive and negative years representing the pressure variability is indicated by white lines. These NAO centers of action reach GCM (ERA-I) SLP differences between positive and negative conditions of about $12.5(17.5) \mathrm{hPa}$ in the IL region and $7.5(10.0) \mathrm{hPa}$ in the $\mathrm{AH}$ region. They do not coincide with the highest and lowest SLP values in the neutral state but are situated near the $3 \times 3$ GCM grid cell matrices used for index calculation (see Fig. 2). This supports the choice of these SLP centers for index calculation. 
(a) Index values of CanESM2-LE

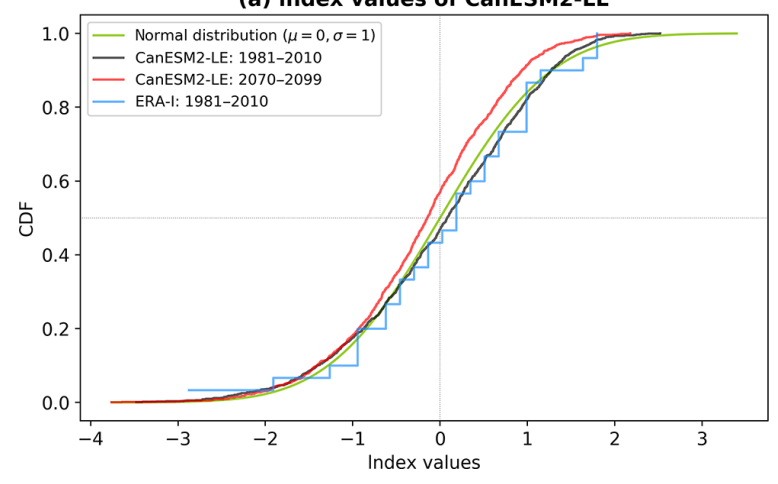

(b) Pairwise correlations among members

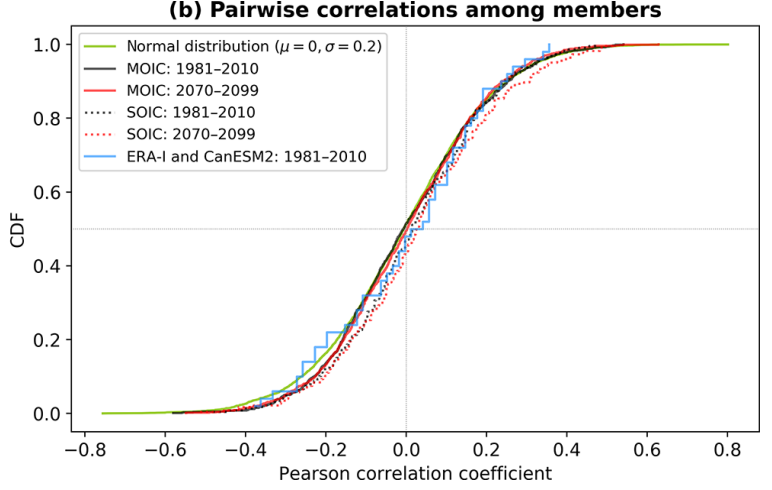

Figure 3. Cumulative density functions (CDFs) of NAO index values. (a) Distribution of all CanESM2-LE $(n=50 \times 30$ per period) and ERA$\mathrm{I}(n=30)$ NAO index values. (b) Pairwise correlations among member NAO index time series from the same ocean families (SOICs, dotted lines, $n=225$ ), from different ocean families (MOICs, solid lines, $n=1000)$ and between ERA-I and all CanESM2 members $(n=50)$. Black: 1981-2010 CanESM2-LE, red: 2070-2099 CanESM2-LE, blue: 1981-2010 ERA-I, green: normal distribution with $\mu=0$ and $\sigma=1$ in panel (a) and $\sigma=0.2$ in panel (b).

Under projected future climate conditions, SLP rises over large parts of the North Atlantic and shows less variability (see Fig. 4g-i). Future positive phases tend to be weaker as SLP shows a marked increase in the northern NAO node region. Negative phases exhibit SLP decreases in both node regions, although with larger changes near IL, resulting in negative phases to become slightly weaker as well.

Having established a reasonably plausible representation of the NAO in the driving data, the next step is to evaluate the large-scale NAO pattern in the RCM data. This is achieved by analyzing the deviations of RCM and driving data SLP variability. Figure 5 maps the RMSD between driving data and RCM SLP during 1981-2010 for driving data ERA-I (Fig. 5a) and CanESM2-LE (Fig. 5b), and CanESM2LE in 2070-2099 (Fig. 5c). An $O(1)$ value of RMSD would indicate a poor reproduction of the SLP signal in the RCM because the RMSD between the RCM and driving data SLP is of the same order as the variability of the SLP in the driving data. Values of RMSD $\ll 1$, on the other hand, would indicate a good reproduction of the SLP signal in the RCM because it suggests that the RCM is tracking the variability in the driving data. With this understanding, it can be seen that the large-scale SLP pattern is reasonably well represented in most parts of the entire ClimEx domain for both driving data sets and both periods (significant at $p \leq 0.05$ using a $t$ test with a false detection rate $<0.1$ to account for multiple hypothesis testing, see Wilks, 2016). All subpanels in Fig. 5 show an RMSD increase towards the south, indicating that in these regions the control exerted by the lateral boundary conditions on the CRCM5 internal solution appears to be weaker. The RMSD is larger in the CanESM2/CRCM5 combination than in the ERA-I/CRCM5 combination and slightly increases in the future period in the southern parts (Fig. 5c). The differences of the spatial patterns are most likely due to different large-scale SLP patterns in both driving data sets which are in parts visible in Fig. $4 a$ and d. In the CEUR do- main (red box in Fig. 5), however, errors are low in general, and therefore the NAO pattern of the driving data may be assumed to be correctly incorporated there. It is thus reasonable to continue with the evaluation of $\mathrm{nSAT}$ and PR responses in the CEUR domain.

\subsubsection{Local climate response to the NAO}

nSAT and PR spatial responses as revealed in the ERAI data are generally reproduced under current climate conditions in CanESM2-LE and CRCM5-LE (see Figs. 6-8). The highest magnitudes of the NAO responses (i.e., the slope of the regression line, $\alpha_{1}$, introduced in Eq. 4) occur in the CRCM5/ERA-I run for all variables. In general, CRCM5 produces stronger $\alpha_{1}$ response values at the local scale than the driving data. Regarding the absolute $\alpha_{1}$ values, the CRCM5-LE mean meets the ERA-I better than the CRCM5/ERA-I run.

Positive NAO conditions are accompanied by winters with warmer temperatures (up to $+2 \mathrm{~K}$ per unit index change; Fig. 6) and less day-to-day nSAT variability compared to neutral conditions (Fig. 7). The mainly positive relationship between nSAT mean and the NAO (Fig. 6) is strongest in the northeastern parts of the domain. Regionally, the NAO explains up to $40 \%-60 \%$ of nSAT mean variability (see also Fig. A2, where the nSAT mean $\alpha_{1}$ share of the entire winter standard deviation of daily temperature values is shown). Explained variance is highest in the CRCM5/ERA-I run and lowest in CanESM2-LE.

The reduction of nSAT variability reaches up to $0.4-0.6 \mathrm{~K}$ in the northeastern continental section, while it is near zero in the southern part of the domain (Fig. 7).

In comparison to the neutral state, positive phases are also accompanied by more humid conditions in the north and drier conditions in the south of the CEUR domain (Fig. 8). The strength of the NAO-PR relationship, expressed by a 
(a) ERA-I SLP

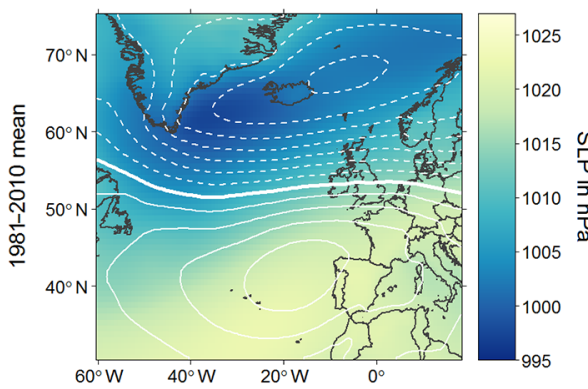

(d) CanESM2-LE SLP mean

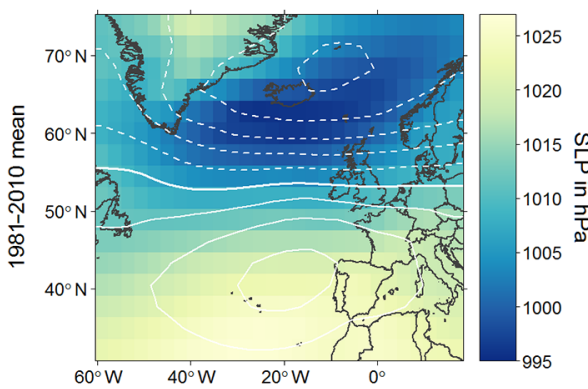

(g) CanESM2-LE SLP mean

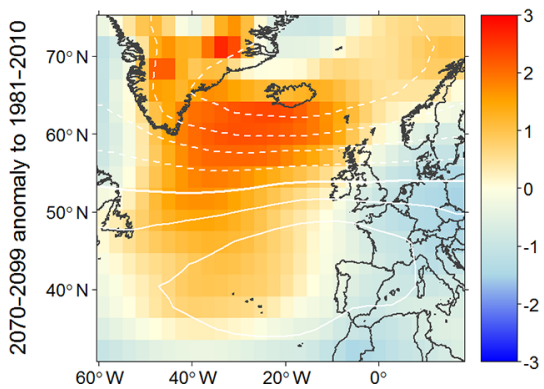

(b) ERA-I NAO+ anomalies

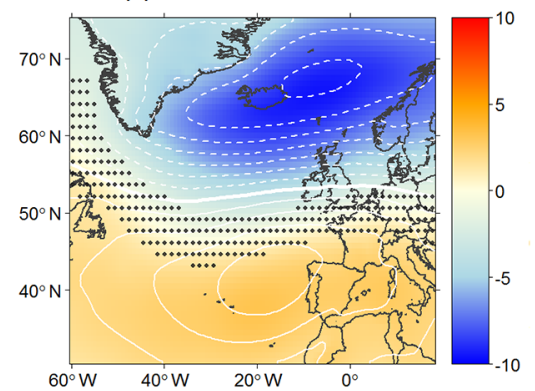

(e) CanESM2-LE NAO+ anomalies

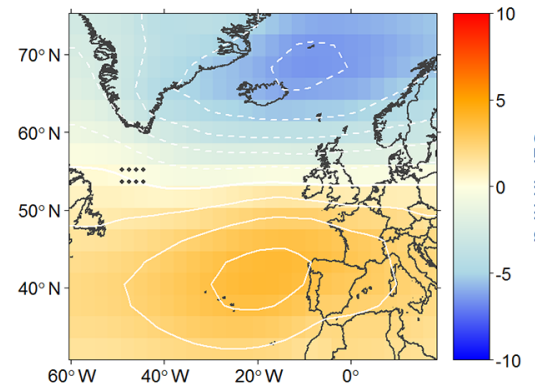

(h) CanESM2-LE NAO+ anomalies

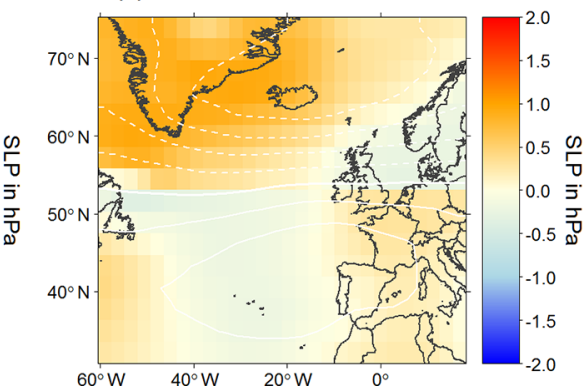

(c) ERA-I NAO- anomalies

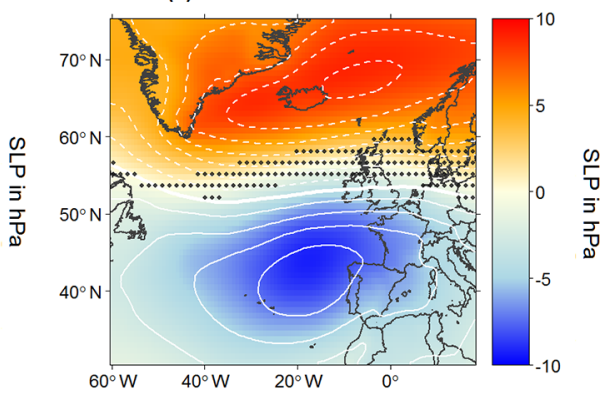

(f) CanESM2-LE NAO- anomalies

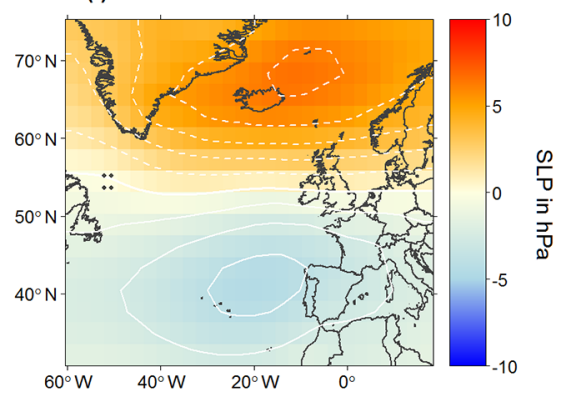

(i) CanESM2-LE NAO- anomalies

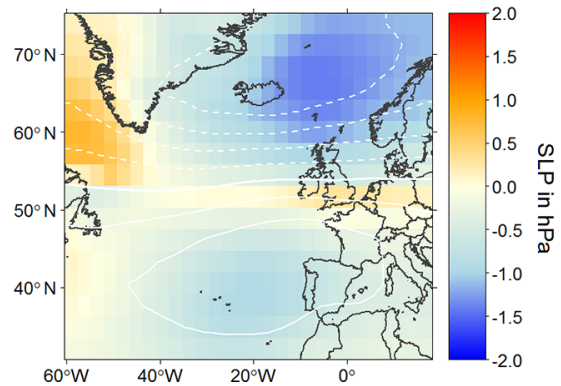

Figure 4. NAR winter mean SLP (hPa) composites in ERA-I (a-c) and CanESM2-LE (d-i) data showing long-term neutral conditions (a, d, g), NAO positive (b, e, h) and negative anomalies (c, f, i), (a-f) for 1981-2010 and (g-i) 2070-2099 changes with respect to 1981-2010 in GCM data. White isolines indicate the difference between positive and negative anomalies by a step of $2.50 \mathrm{hPa}$, as, e.g., in Hurrell (1995); solid: positive, dashed: negative, bold line: zero. Grey stippling in subpanels (b-c) and (e-f) indicates regions where the anomaly is smaller than the standard error of the composite samples.

(a) RMSD ERA-I/CRCM5 (1981-2010)

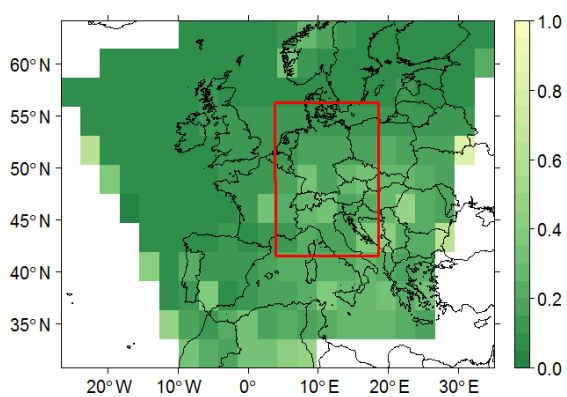

(b) RMSD CanESM2/CRCM5 (1981-2010)

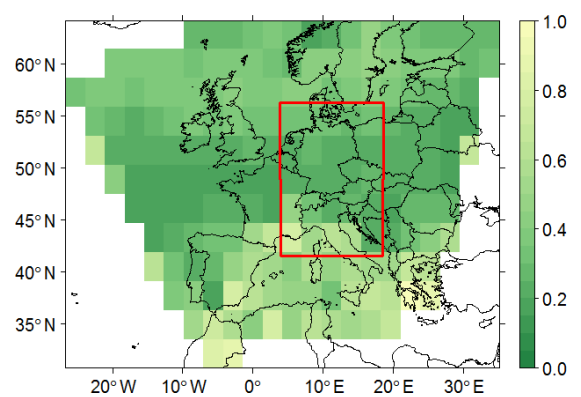

(c) RMSD CanESM2/CRCM5 (2070-2099)

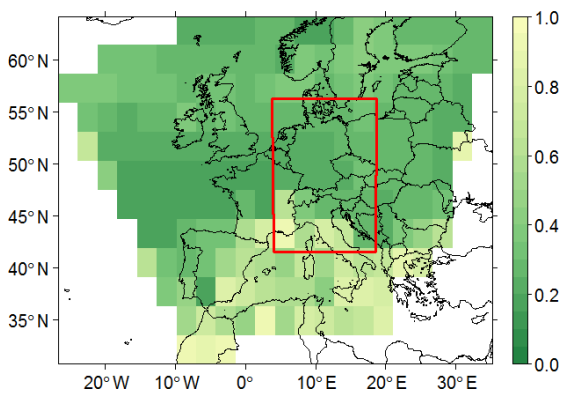

Figure 5. RMSD of monthly SLP differences between driving data and CRCM5 members, calculated following Eq. (2). Coloring: RMSD $\leq 1$ significant at $p \leq 0.05$ with a false detection rate smaller than 0.1 (see Wilks, 2016): (a) for driving data ERA-I (1981-2010, one realization), (b) for driving data CanESM2-LE (1981-2010, 50 members) and (c) for driving data CanESM2-LE (2070-2099, 50 members). Red box: position of CEUR domain. 
(a) ERA-I (hist)

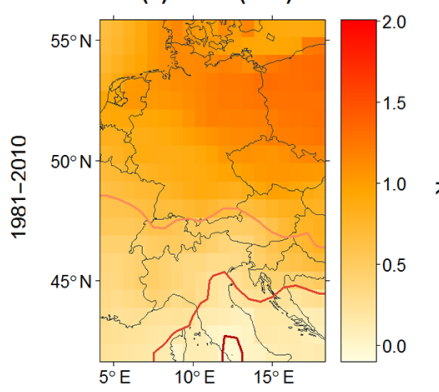

(c) CanESM2-LE mean (hist)

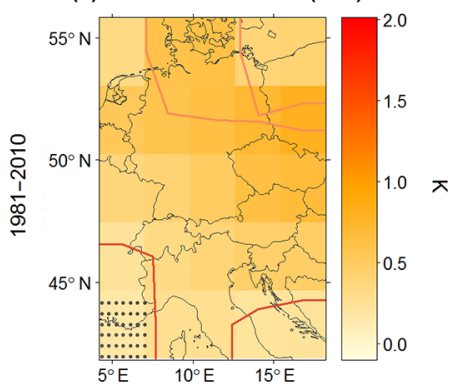

(g) CanESM2-LE mean (fut)

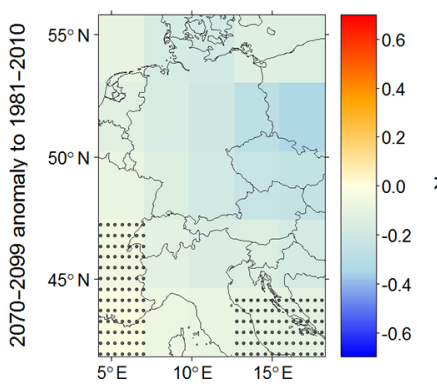

(b) CRCM5/ERA-I (hist)

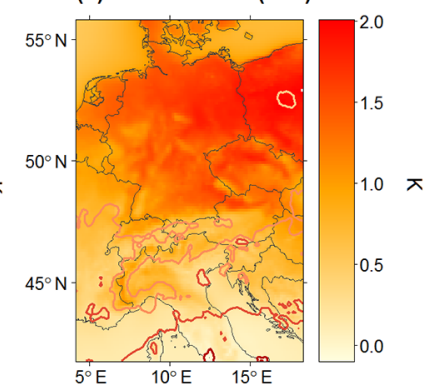

(d) CRCM5-LE mean (hist)
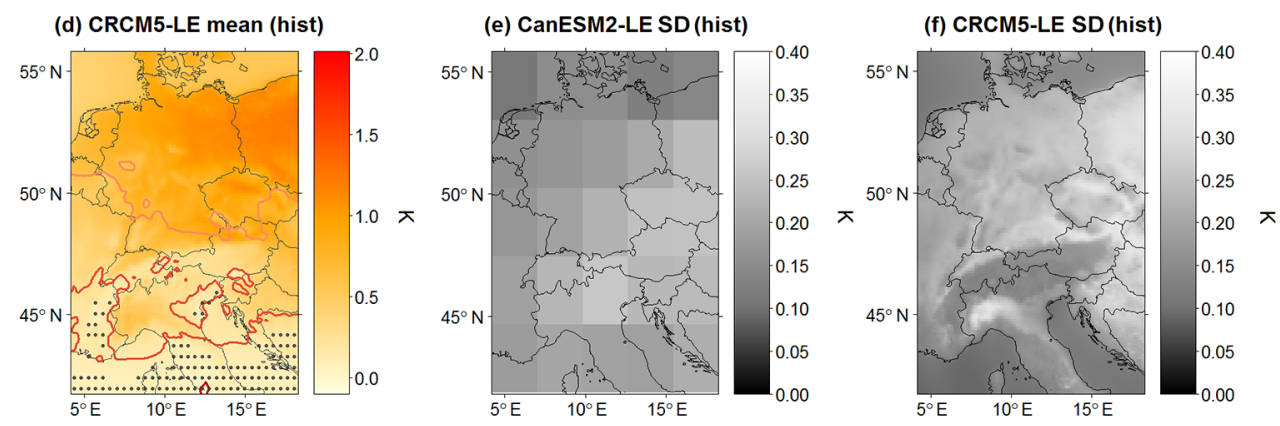

(h) CRCM5-LE mean (fut)

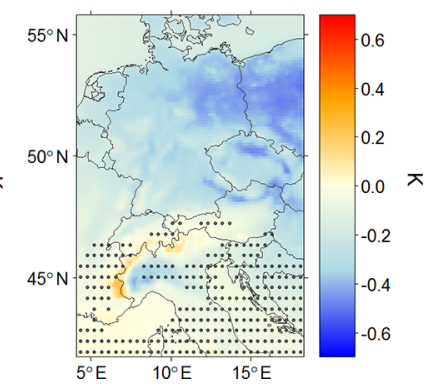

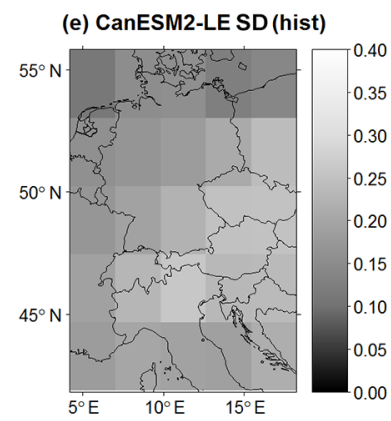

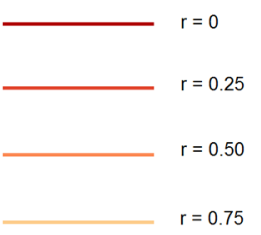

(i) CanESM2-LE SD (fut)

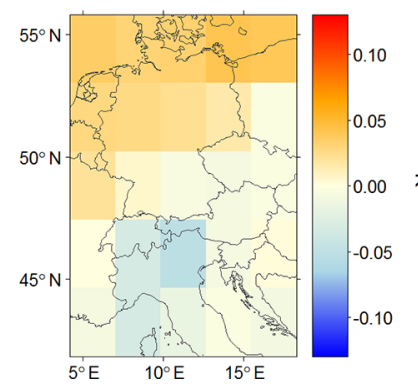

(j) CRCM5-LE SD (fut)

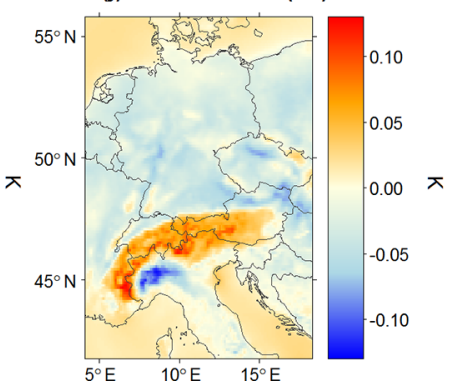

Figure 6. Spatial patterns of change in nSAT mean $\left(\alpha_{1}\right.$ in K) for a unit change in the NAO index for ERA-I, CRCM5/ERA-I, CanESM2LE and CRCM5-LE in 1981-2010 (a-f) and the change in 2070-2099 with respect to 1981-2010 (g-j). Both 50-member ensembles are represented with ensemble mean $(\mathbf{c}-\mathbf{d}, \mathbf{g}-\mathbf{h})$ and standard deviation $(\mathrm{SD}, \mathbf{e}-\mathbf{f}, \mathbf{i}-\mathbf{j})$ representing the inter-member spread. Reddish lines in the ensemble mean maps represent the Pearson correlation between nSAT mean and the NAO index at an increment of 0.25 ; red shadings - see legend in upper right panel. Grey stippling in the ensemble mean maps indicates regions where SNR $<1$, with SNR being the signal-to-noise ratio between the 30-year ensemble mean and SD of GCM- and RCM-LEs in both time periods. Stippling will be explained in more detail in Sect. 3.2.2.

Pearson correlation coefficient $(r)$, is not affected by topography in any of the models within the domain; only the pivotal line crossing Europe is following the Alpine ridges (see solid dark line in Fig. 8a-d). The change between positive and negative $r$ and $\alpha_{1}$ occurs within a very narrow region. Within CanESM2-LE, this zero-line is shifted northwards compared with ERA-I, CRCM5/ERA-I and CRCM5-LE. As is visible in Fig. 8, higher $\alpha_{1}$ values in mountainous regions indicate strong NAO responses related to orography. Regionally, the NAO accounts for $40 \%-50 \%$ of total PR sum variance, in both positively and negatively correlated regions. In CRCM5-LE, single spots in mountainous regions (e.g., in the Dinaric Alps) show extremely high PR sum $\alpha_{1}$ values (up to $\pm 220 \mathrm{~mm}$ per unit index change). In these parts the longterm mean PR sums are also very high. This stresses the more detailed production of geographical features but also the ten- dency to evolve local extreme values in the high-resolution RCM (see similar results for local daily extreme precipitation in Leduc et al., 2019), which may even be noted in the (spatially aggregated) bias towards the GCM (see Fig. A1f). PR sum shows only weak correlations in the central region of the CEUR domain.

The mean state of nSAT and PR changes in the transient climate simulation towards warmer and moister conditions with less intra-seasonal variability of nSAT. For a detailed description of the future climate evolution (though for 2080-2099) in Europe within CRCM5-LE, see Leduc et al. (2019). Future NAO-climate relationships weaken in general compared with the historical ones for all variables as can be inferred from the ensemble mean changes in panels of Figs. $6 \mathrm{~g}-\mathrm{h}, 7 \mathrm{~g}-\mathrm{h}$ and $8 \mathrm{~g}-\mathrm{h}$. The spatial patterns of NAOinduced change do not change considerably between both 
(a) ERA-l (hist)

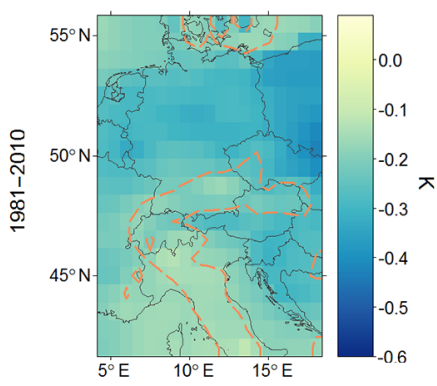

(c) CanESM2-LE mean (hist)

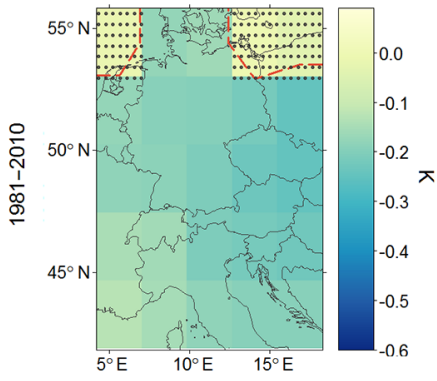

(g) CanESM2-LE mean (fut)

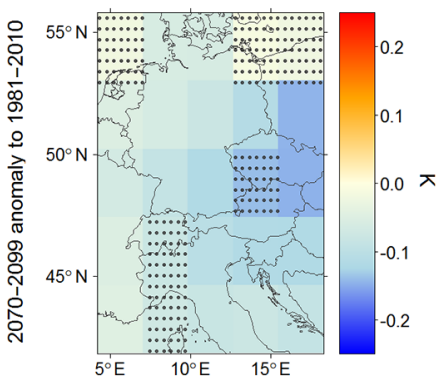

(b) CRCM5/ERA-I (hist)

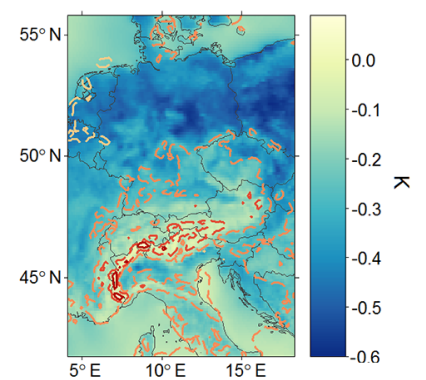

(d) CRCM5-LE mean (hist)

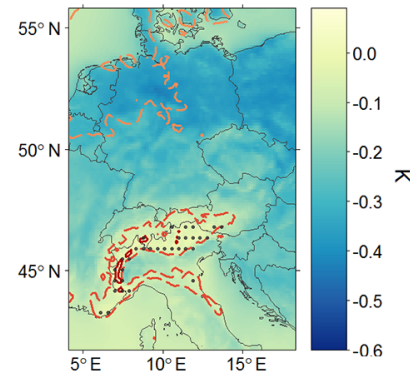

(h) CRCM5-LE mean (fut)

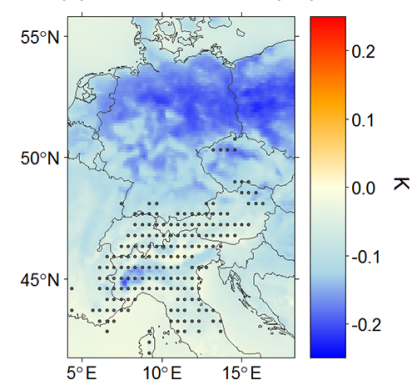

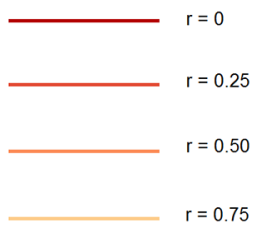
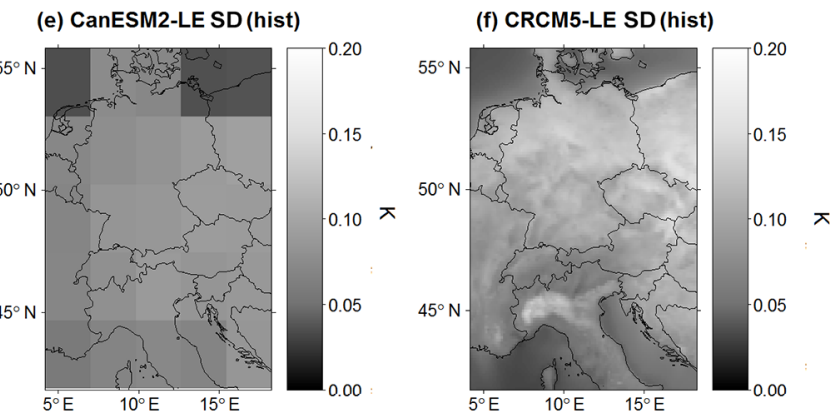

(i) CanESM2-LE SD (fut)

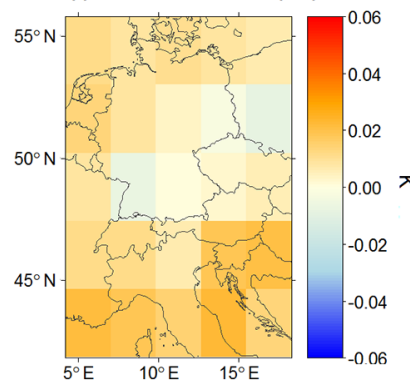

(j) CRCM5-LE SD (fut)

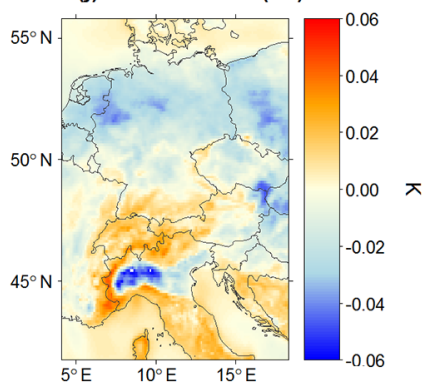

Figure 7. Like Fig. 6 but for nSAT SD ( $\alpha_{1}$ in K). Dashed lines of correlation coefficients indicate negative values. Note that the difference maps for CanESM2-LE and CRCM5-LE mean are calculated using absolute values.

periods. The response to the $\mathrm{NAO}, \alpha_{1}$, is clearly reduced in nSAT mean as well as nSAT SD, and there is also a reduction in PR sum change (Figs. 6g-h, $7 \mathrm{~g}-\mathrm{h}$ and $8 \mathrm{~g}-\mathrm{h}$.).

\subsection{Internal variability at the GCM and RCM scale}

The next section focuses less on the ensemble mean changes but rather on their internal variability. The representation of internal variability in the GCM and RCM regarding the responses to the NAO in CEUR and subset regions NE, BY, SE is assessed via the inter-member spreads of CRCM5-LE and CanESM2-LE, and their differences.

\subsubsection{Multi-member ensemble}

CanESM2-LE reproduces typical NAO index characteristics. Figure 9 summarizes several statistics for all $50 \mathrm{GCM}$ members as multiples of the reference, i.e., ERA-I, value. Generally, the ensemble meets the ERA-I value in all aspects of the NAO index. However, some GCM members only reach half of the ERA-I teleconnectivity values (minimum correlation between AH/IL time series: $r=-0.281$, not significantly different from zero at $p \leq 0.05$ using a $t$ test; ERAI $r=-0.699$ ). This finding is especially interesting as this metric quantifies the strength of the NAO within the individual members. The inter-member spread of the teleconnection strength does not change significantly over time, despite the SLP changes over the North Atlantic. The 20702099 NAO index exhibits less interannual variability, less positive phases, more neutral phases and a relative increase of negative phases but with reduced mean values (see also Fig. 3a).

The spatial NAO responses also show a considerable degree of internal variability. Its spatial distribution expressed by diverging ensemble members can be derived from Figs. 6e-f, 7e-f and 8e-f, presenting spatially distributed ensemble SD as a measure of inter-member spread. Locally, the RCM shows considerably higher spreads than the GCM. Largest deviations for nSAT mean are found in continental regions of CEUR, but they do not simply correspond to high 


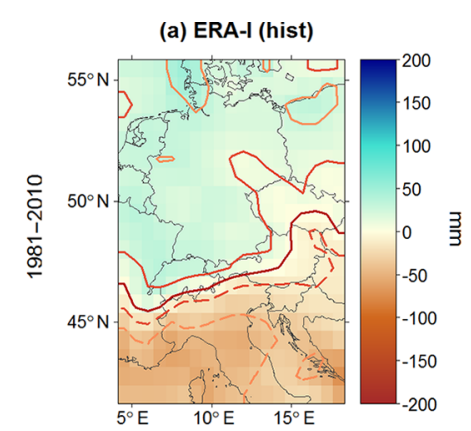

(c) CanESM2-LE mean (hist)

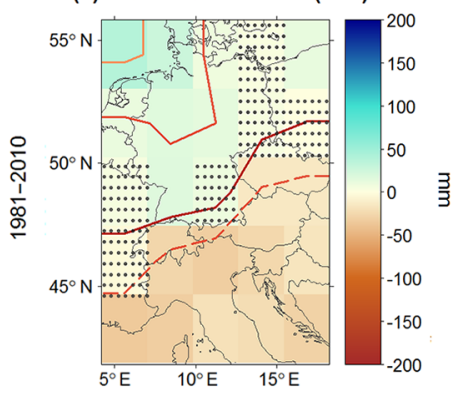

(g) CanESM2-LE mean (fut)

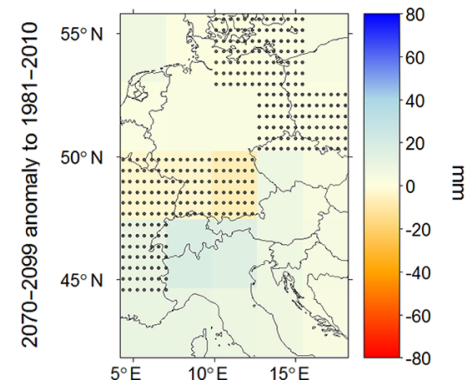

(b) CRCM5/ERA-I (hist)

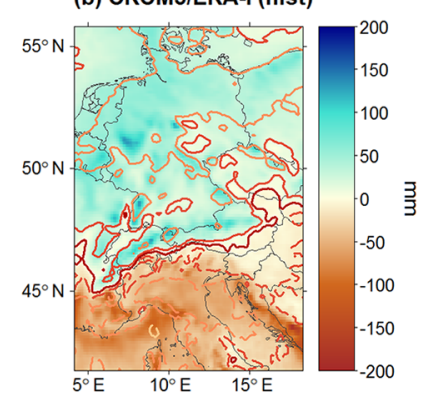

(d) CRCM5-LE mean (hist)

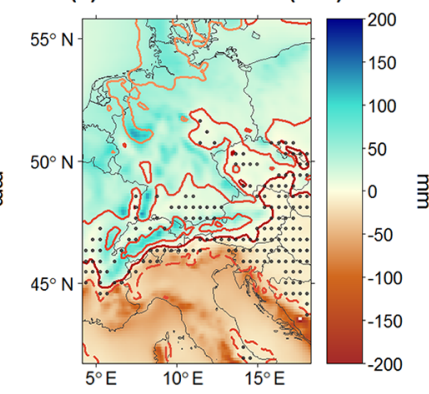

(h) CRCM5-LE mean (fut)

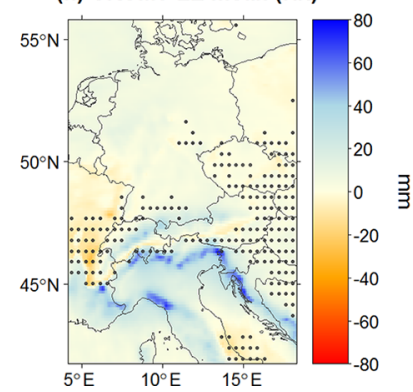

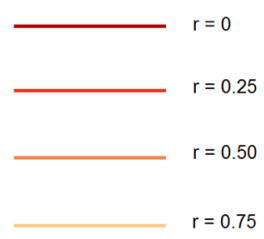

(e) CanESM2-LE SD (hist)
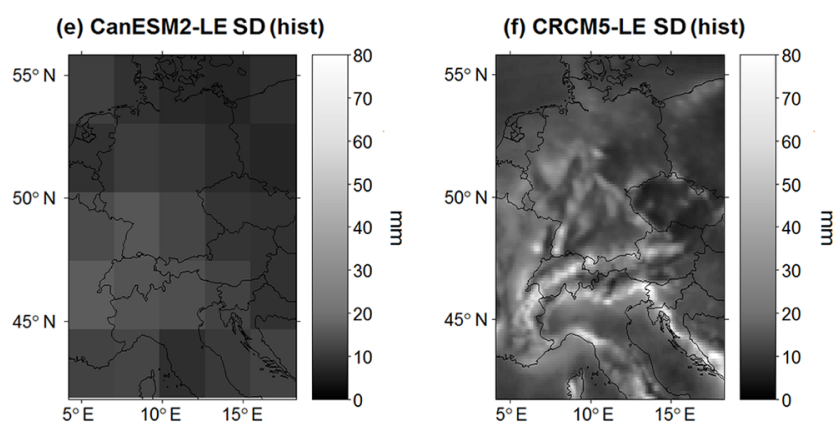

(j) CRCM5-LE SD (fut)
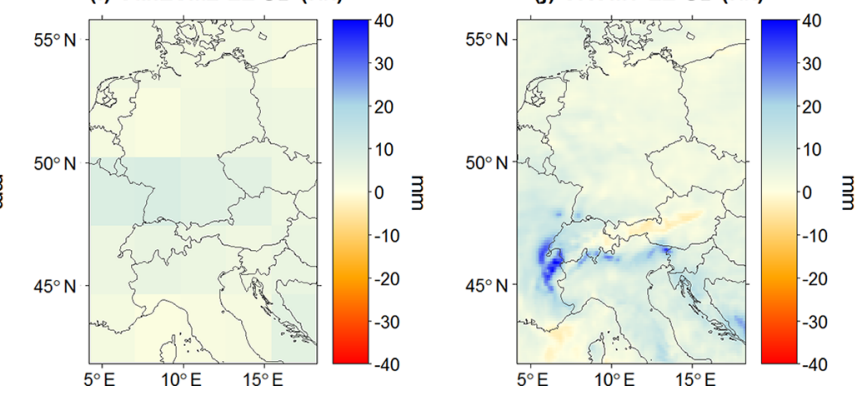

Figure 8. Like Figs. 6 and 7 but for PR sum $\left(\alpha_{1}\right.$ in mm). Dashed lines of correlation coefficients indicate negative values. Note that the difference maps for CanESM2-LE and CRCM5-LE mean are calculated using absolute $\alpha_{1}$ values and that the color bar in the bottom row is flipped compared with Figs. 6 and 7.

or low $\alpha_{1}$ (see also Fig. A3a-d). Low inter-member spread corresponds mostly to Alpine and sea regions.

The stippling in Figs. 6-8c-d and g-h indicates regions where the variability among the members is larger than the ensemble mean response, i.e., where the signal-to-noise ratio (SNR) between ensemble mean and SD lies below 1 . For nSAT mean, the SNR exceeds 1 in most regions north of the Alps (Fig. 6c, d, g and h). nSAT SD shows SNR $<1$ in the northern parts of the CanESM2-LE data (Fig. 7c, g) and in the Alpine region of the CRCM5-LE data (Fig. 7d, h). This variable shows a strong linear relationship between LE mean and SD (Fig. A3e-h). Regarding PR sum, RCM members vary most in regions with highest absolute $\alpha_{1}$ values and altitudes, but there is no clear dependence in the GCMs (Fig. A3i-1). An east-west corridor of SNR values below 1 accompanies rather low $\alpha_{1}$ values of PR sum (Fig. 8c, d, g, and $\mathrm{h}$ ).

In addition to future changes in the NAO responses ensemble means, there is also a change in the spatial distribu- tion of the inter-member spread expressed as ensemble SD (Figs. $6 \mathrm{i}-\mathrm{j}, 7 \mathrm{i}-\mathrm{j}$ and $8 \mathrm{i}-\mathrm{j}$ ).

To further investigate the inter-member spread, Fig. 10 illustrates the Pearson correlation coefficients $r$ between the NAO index and subset regions for nSAT mean or PR sum in GCM- and RCM-LEs separately. In these boxplots, the variability among the members is illustrated by the box size, i.e., the interquartile distance. Both ensemble inter-member spreads generally envelope the ERA-I value (dashed line) of the given region, apart from GCM hist in Fig. 10b. This general finding does not change in the projected future climate: most boxes and whiskers keep their size, only GCM nSAT in the NE region is characterized by a larger range in the future (significant at $p \leq 0.05$, using an $F$ test for comparison of variances). Some of the ensemble mean values exhibit a significant shift towards lower $r$ values in the future for both models for nSAT mean and PR sum (see text insertions: CanESM2(hist, fut) and CRCM5(hist, fut)). An unpaired Mann-Whitney/ $U$ test is applied here as the samples 


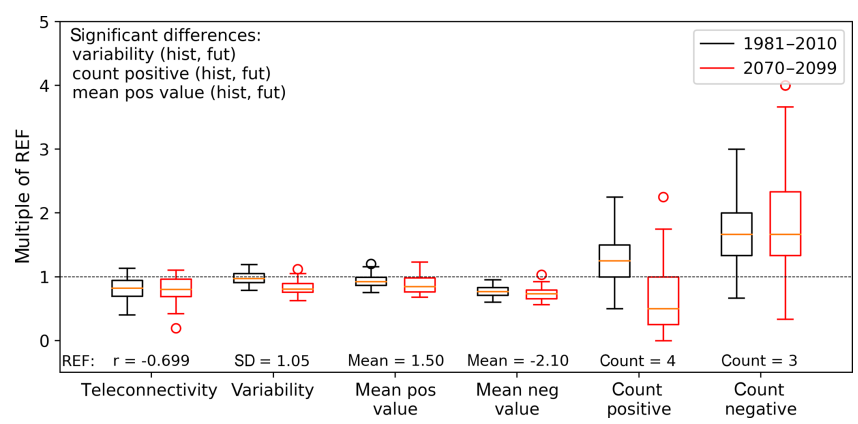

Figure 9. Several index statistics of all 50 CanESM2-LE members expressed as multiples of the respective ERA-I value (ERA-I value set to 1.0): teleconnectivity (Pearson correlation between $\mathrm{AH}$ and IL time series), index variability (expressed as temporal standard deviation of index time series), mean value of all positive (negative) phases and count of all positive (negative) phases per realization. Positive (negative) years are defined by an absolute index value exceeding 1. Text denotes combinations of which the differences are significant at $p \leq 0.05$ using an unpaired Mann-Whitney/U test. Orange line in boxplots is the median.

from hist and fut are seen as being drawn from different climates (since the null hypothesis of independence between hist and fut periods could not be rejected at $p \leq 0.05$ using a $\chi^{2}$ test).

\subsubsection{Change of scales}

Having analyzed GCM and RCM separately so far, the next step is to compare both ensembles. A $\chi^{2}$ test reveals that GCM and RCM samples of $r$ can be seen as significantly dependent in both time frames. The amount of variance explained by the NAO is generally higher in the ERA-I reference than in the RCM ensemble mean. CRCM5-LE enhances the relationship showing higher $r$ and $\alpha_{1}$ values than CanESM2-LE (see Fig. 10 for $r$ and Figs. 6-8 for $\alpha_{1}$ ). This enhancement by CRCM5 is notably independent of the driving data: for both variables, the CRCM5/ERA-I $r$ value (dotted lines in Fig. 10) is also found to be higher than the ERA-I value in most regions (dashed lines in Fig. 10). In all subset regions, the CRCM5/ERA-I $r$ value lies in the upper part (stronger correlations) of the CRCM5-LE ensemble values.

Figure 10 shows that mean $r$ values of RCM (grey filling) and GCM (white) members are significantly different in all subset regions for nSAT mean in both time horizons but only in the NE and BY regions for PR sum; in the SE region, only weak differences between GCM and RCM PR sum $r$ distributions are visible. In NE and BY regions this difference is expressed by higher $r$ values in RCM data, whereas in the SE region lower $r$ values are found in the RCM data (only for nSAT mean). Apart from PR sum in the NE region (both time horizons), no significant difference between the spread amplitudes of GCM and RCM is visible ( $p \leq 0.05, F$ test). The inter-member spread of the correlation between NAO and re- sponse variables is not generally altered during the nesting process.

To evaluate the covariability of CanESM2 and CRCM5 data in the subset regions, time series of the response variables originating from both data sources are correlated member-wise (see Fyfe et al., 2017, for a similar approach). As can be seen in Fig. 11, highest accordance on average is reached for nSAT mean in both periods, indicating that CanESM2-LE and CRCM5-LE show very similar temporal variability for this variable. The covariability of GCM and RCM time series is weaker for PR sum (Fig. 11b) and nSAT SD (Fig. 11c) than for nSAT mean (Fig. 11a) in both periods. Also, the inter-member spread is larger for PR sum and nSAT SD than for nSAT mean. This finding suggests that there is a larger discrepancy in portraying PR sum and nSAT SD in the RCM with respect to the GCM compared with nSAT mean; i.e., the RCM does not generally track the variability induced by the GCM for these variables. The correlations of nSAT mean and PR sum between CanESM2 and CRCM5 subset regions are in general significantly lower under future climate conditions compared with the historical ones, apart from nSAT mean in the BY region and PR sum in the SE region (see text in Fig. 11). For nSAT SD a significant shift of the distribution of $r$ towards higher values is visible, apart from nSAT SD in the BY region. All variables exhibit a future inter-member spread increase, but not all subset regions are affected (e.g., nSAT mean in BY or nSAT SD in SE, Fig. 11). This suggests that under future climate conditions a potential reduction of GCM-RCM covariability needs to be considered, at least for PR sum and (weaker) for nSAT mean.

\section{Discussion}

\subsection{General performance of the model chain}

The ClimEx climate data ensemble is able to reproduce a NAO-like pattern with realistic temporal and spatial characteristics over the North Atlantic and corresponding response patterns in central Europe. Ensemble mean information aggregates several realizations, and so differences towards the single ERA-I realization are to be expected. However, results show that the ERA-I pattern may in general be seen as being "embedded" in the RCM or GCM inter-member spread, implying that the GCM, RCM and reference data share comparable climate statistics.

Regarding temperature, Europe is commonly seen as divided into a region with positive NAO-response correlations in the north and negative correlations in the south (see, e.g., Woollings et al., 2015). The first is found in the herepresented results; the latter is not clearly visible in the chosen domain. nSAT SD is correlated negatively with the NAO, pointing towards less temperature variability in winters with positive NAO phases and a higher variability during negative phases. Correlations of PR sums and NAO are in accordance with the prevalence of large-scale (frontal) precipitation in 

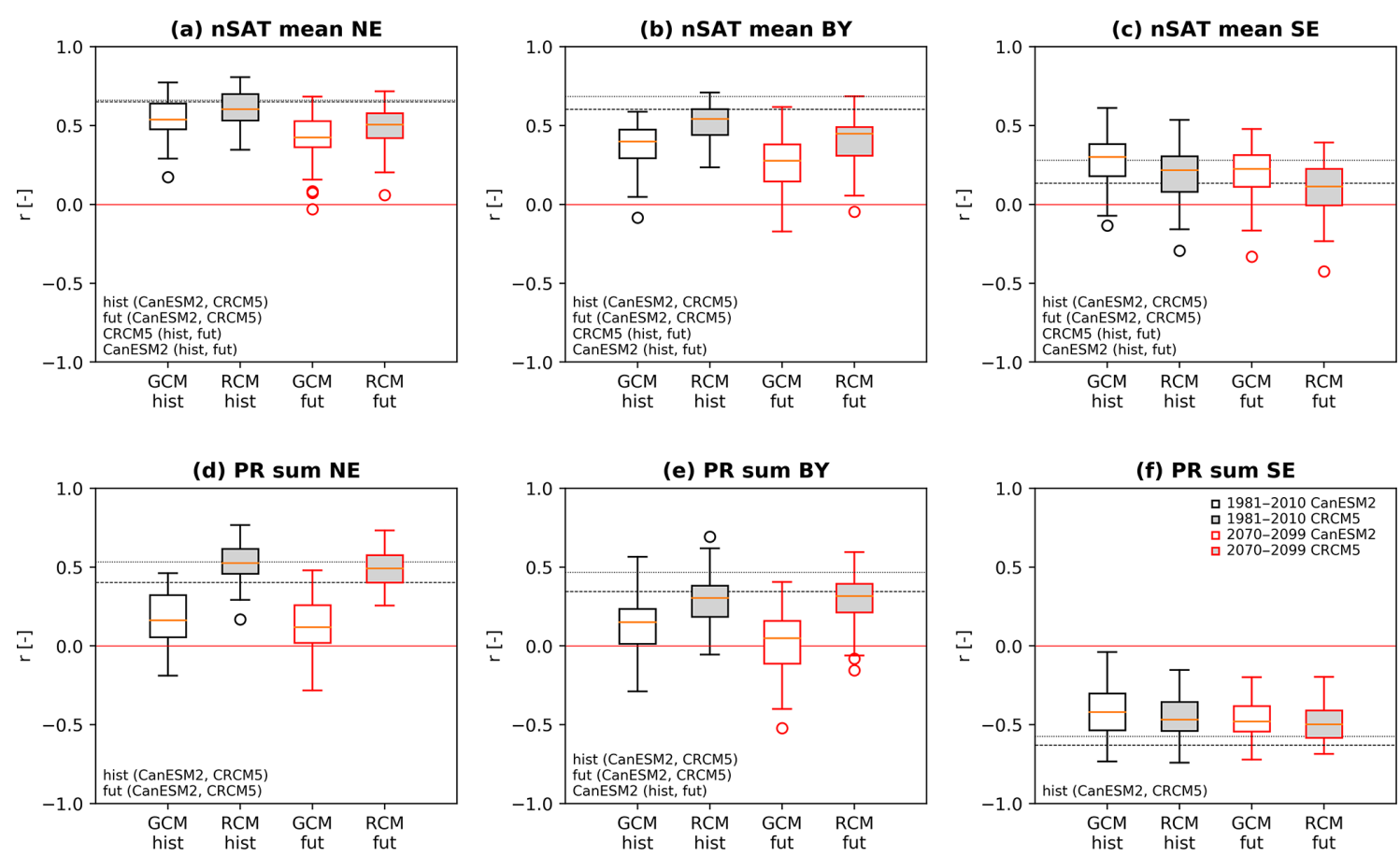

Figure 10. Boxplots of nSAT mean (a-c) and PR sum (d-f) showing Pearson correlation $(r)$ with the NAO index of 50 CanESM2-LE (white filling) and CRCM5-LE (grey filling) realizations for three regions (NE, BY, SE) in historical (black outlines) and future (red outlines) time horizons. Dashed (dotted) horizontal lines indicate the ERA-I (CRCM5/ERA-I) value; text denotes combinations of which the differences are significant at $p \leq 0.05$ using an unpaired Mann-Whitney/ $U$ test for the comparison between hist and fut periods and a paired Wilcoxon test for the comparison between CanESM2-LE and CRCM5-LE. Orange line in boxplots is the median. For regions NE, BY and SE, see Fig. 2.
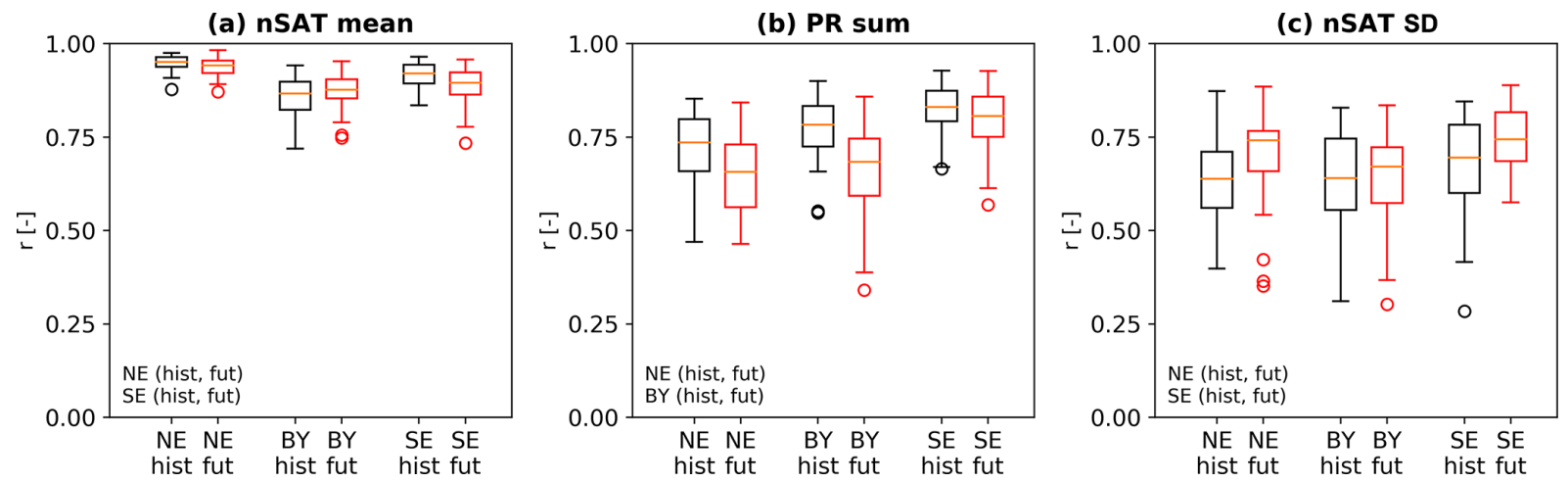

Figure 11. Temporal covariability of CanESM2-LE and CRCM5-LE subset regions in all 50 members. Each boxplot represents 50 Pearson correlation coefficients of the time series of variables nSAT mean (a), PR sum (b) and nSAT SD (c) in the subset regions between CanESM2-LE members and the corresponding CRCM5-LE members. Time periods used for correlations are 1981-2010 (hist, black) and 2070-2099 (fut, red). Text denotes combinations of which the differences are significant at $p \leq 0.05$ using an unpaired Mann-Whitney/U test. Orange line in boxplots is the median. For regions NE, BY and SE, see Fig. 2.

winter which might be affected if the large-scale circulation is altered due to the NAO.

The strong SLP gradient under neutral NAO conditions over the North Atlantic noted in CanESM2-LE suggests an overestimation of the local atmospheric circulation with too strong westerlies. Similar model biases are widely reported (see, e.g., Ruprich-Robert and Cassou, 2015; Stephenson et al., 2006; Reintges et al., 2017; Ulbrich et al., 2008). Since the NAO index was obtained from raw SLP data, it contains the contribution of the NAO but possibly also of microclimatic noise or other teleconnection patterns like the East Atlantic (EA) and the Scandinavian pattern (SCA) which interact with the NAO and exert a notable control on the North Atlantic SLP gradient according to Moore et al. (2013). These 
authors investigated the contributions of the North Atlantic teleconnections NAO, EA and SCA in reanalysis data by separating them with empirical orthogonal functions. The authors found that the "pure" NAO accounts for about onethird of winter SLP variability, and the second and third leading modes for roughly $20 \%$ and $15 \%$, respectively (see also Comas-Bru and McDermott, 2014). Thus, the results shown here may be seen as representing the superposition of these atmospheric modes.

The fidelity of NAO responses further depends on two aspects: (i) the goodness of representation of the large-scale NAO-related SLP pattern in CEUR and (ii) the strength of the linear relationship between the NAO and the response variables. The first point is addressed by a good representation of the SLP pattern in RCM data (see Fig. 5). The second point may be targeted by a combination of the strength of the responses (correlations $r$ ) and the response values themselves $\left(\alpha_{1}\right)$ : NAO responses in the CEUR domain of all data sets are most reliable in regions where a strong linear relationship between the NAO and the response variable may be assumed. This may be the case if the correlation coefficient between the NAO index and the variable time series on the given grid cells is significantly different from zero. However, linearity does not apply under all conditions. For example, particularly strong negative NAO phases with low-ice conditions in the Arctic coincide with cooling in Europe that is weaker than expected from a linear relationship due to an accompanying warming over Siberia (Screen, 2017). Low correlation values may also suggest that climate variability in these regions is only to a small fraction influenced by the $\mathrm{NAO}$ in this data set and period under consideration. In these cases, the NAO as expressed by the North Atlantic SLP gradient in this study is not the most important contributor and the noise, $\varepsilon_{Y}$ in Eq. (4), is dominant.

Historical changes induced by the NAO $\left(\alpha_{1}\right.$, all data sources) are generally in accordance with observed composite anomalies (see also Fig. A4) but most so in regions with significant correlations. Thus, the future change of nSAT and PR per unit index change is most valid where correlations are high and where the NAO related responses emerge from internal variability (i.e., SNR $>1$ ). Of course, $\alpha_{1}$ and composite maps are not identical, as on the one hand the average index value that accompanies nSAT and PR anomalies is not the same ( \pm 1 for $\alpha_{1}$ but +1.498 and -2.103 for ERA-I composites; see Fig. 9). On the other hand, $\alpha_{1}$ estimates a change which is singularly generated by the NAO index in a linear relationship, while composite maps originate from raw data which might include further influences.

\subsection{Nesting approach}

NAO response patterns are similar within CanESM2-LE and CRCM5-LE, but some deviations remain due to differences in model parameterization and spatial resolution. Another possible explanation could be that the control exerted by
CanESM2 through the CRCM5 lateral boundary conditions is insufficient, but this is unlikely given the relatively small CRCM5 domain implying stronger lateral boundary conditions control (Leduc and Laprise, 2009), in addition to the strong spectral nudging of large scales that was applied in the production of CRCM5-LE (Leduc et al., 2019). Also, the large-scale SLP pattern over CEUR shows no large errors in CRCM5-LE with respect to its driving data sources (see Fig. 5) and temporal correlation of GCM and RCM time series are generally high. Nevertheless, the influence of the lateral boundary conditions regarding SLP appears to vary over the CRCM5 domain, being a bit weaker in the southern part. It is worth noting that this feature is less pronounced when CRCM5 is driven by ERA-I as compared with CanESM2, highlighting the importance to investigate further the interactions between global atmospheric circulation, surface forcings (e.g., topography and land-sea contrasts) and local feedbacks.

CRCM5 reproduces the response structures much finer than CanESM2 and adds some robust high-resolution geographical features which are clearly visible within the ensemble mean. Apart from the coarser pattern resolution, there is also a shift in the spatial climate patterns in CanESM2-LE within the CEUR domain with respect to ERA-I data which are not found in CRCM5-LE: for example, typical continental climate features, such as high nSAT variability (as indicated in Fig. 6), are shifted southwards in CanESM2-LE with respect to CRCM5-LE data (or ERA-I). This shift may be explained by the fact that due to coarser spatial resolution the GCM topography shows land grid cells where the Mediterranean or the Baltic Sea extend in ERA-I and CRCM5; thus, in the GCM, the continent Europe also occupies a region which is sea in ERA-I. Assuming that the land-sea distribution affects the climate evolution, the GCM also experiences a geographical shift of climatic characteristics (such as continental properties) compared with the ERA-I and RCM data within the study domain. Another example is the dividing line for NAO-PR sum relations (see Fig. 8), which shows a displacement in the GCM compared with the RCM. This displacement is related to the GCM orography which deviates due to the coarser spatial resolution in shape, position and height from the RCM orography. These findings suggest that similar responses of GCM and RCM to the NAO may not be visible at the same geographical location (i.e., coordinates) but under similar geographical conditions (exposition, altitude, distance to sea). Continuing this thought, the RCM reproducing the spatial climatic patterns in the "correct" location is another expression of the RCM added value for regional- or local-scale analyses. However, for general statements on this issue, analyses on a larger domain would be necessary.

On the regional scale, the correlations in CRCM5 are significantly stronger in several regions than in CanESM2 (Figs. 6-8). These differences are not evened out by spatial aggregation. Thus, in CRCM5-LE, more variance is ex- 
plained by the NAO (i.e., by large-scale circulation) than in CanESM2-LE. Explained variance is also higher in the single realizations of ERA-I and CRCM5/ERA-I than in the ensemble mean of GCM and RCM.

\subsection{Internal variability}

In general, the $50 \mathrm{NAO}$ signals from the atmospheric "inflow" as given by the GCM boundary conditions are correctly translated into 50 regional responses of the RCM regarding the range of internal variability.

The large ensemble internal variability favors a smoothing of structures in the ensemble mean. Nevertheless, as the ensemble mean (GCM and RCM) reproduces patterns very similar to the observed ones, the atmospheric dynamics behind can be regarded as correctly reproduced in all members.

When looking at spatially explicit ensemble SD, the RCMLE exhibits higher ensemble SD values than the GCM. This is in accordance with Giorgi et al. (2009) who stated that internal variability at finer scales tends to be larger compared with coarser scales. However, the amplitude of the inter-member spread of NAO-response correlations in the aggregated RCM and GCM subset regions is similar. Thus, the range of internal variability regarding the strength of the NAO-response relationship is transferred during nesting and the added CRCM5 internal variability (Leduc et al., 2019) does not significantly alter it. However, the ensemble values are shifted towards significantly higher $r$ values in the RCM compared with the GCM in both time frames but not in the SE region.

\subsection{Climate change}

The results show that historical and projected future climate statistics deviate such that the comparison of relationships in both periods remains difficult: the NAO pattern changes, NAO index variability and nSAT and PR responses are reduced in the future climate simulation. Also the uncertainty range of the signals does not change significantly in the future horizon.

With the here-presented results, it can be argued that the internal variability of more complex parameters (such as the NAO-response relationship quantified via Pearson correlation) shows no significant changes between historical and future periods. When looking at the spatial distribution of $\alpha_{1}$ ensemble SD, however, several regions show slight future increases or decreases which are not necessarily consistent between GCM and RCM.

It has to be added that this study evaluated two 30-year blocks rather than continuous time series, treating the NAOresponse relationship and the inter-member spread as stationary during these blocks such that the inter-member spread of both periods represents generalized conditions for 19812010 and 2070-2099. According to Comas-Bru and McDermott (2014), potential non-stationarity in NAO-response re- lationships can at least partly be attributed to influences of the EA/SCA patterns on the NAO and especially the geographical position of the North Atlantic SLP gradient.

The relative prevalence of negative index phases in the future period occurs in correspondence to a generally strengthened high-pressure ridge over the North Atlantic and especially Greenland (see Fig. 4g). The latter feature is supposed to be related to the emergence of negative index phases (Hanna et al., 2015; Woollings et al., 2010; Gillett and Fyfe, 2013; Cattiaux et al., 2013; Screen, 2017). Another relationship ties the emergence of negative NAO index phases to reduced sea ice extents: Warner (2018) found that particularly October sea ice extent over the Barents/Kara Sea is positively correlated with the NAO in that it leads to strengthened IL and $\mathrm{AH}$. Consequently, a reduced sea ice extent is associated with negative NAO phases, but this relationship is not simply linear (Warner, 2018). For example, Screen (2017) notes that negative NAO events tend to be stronger during winters with low sea ice extents. The NAO-sea ice relationship may follow from sea ice effects on the stratospheric polar vortex or from tropospheric Arctic amplification which reduces the meridional temperature gradient leading to a weakened, more wavy jet stream in the midlatitudes (Warner, 2018). CanESM2-LE is known to show a low bias regarding Arctic sea ice in all seasons compared with observations (Kushner et al., 2018), but it follows quite correctly the observed downward trend (Kirchmeier-Young et al., 2017) and leads to a clear reduction of sea ice in the 2070-2099 horizon compared with 1981-2010 in the entire Arctic and also the Barents/Kara Sea, as is verified with the CanESM2 variable "sea ice concentration" for this study (not shown).

An increasing frequency (relative to positive phases) of negative NAO events as noted in the presented results favors more cold and harsh winters in theory due to the advection of continental Eurasian air masses (Screen, 2017) which is in great contradiction to projected future background conditions (warmer, moister, see Leduc et al., 2019) that would rather, likewise following from theory, accompany positive phases. On the other hand, the response to NAO impulses is clearly reduced for nSAT mean, PR sum and nSAT SD. A coherent explanation for this discrepancy might be that as correlations weaken, the Eurasian influence (advection of cold, dry air masses) during negative phases may be repressed or weaker in its occurrence than now or, as indicated by Screen (2017), is actually increasing warmer air mass advection. As less nSAT and PR variance is explained by the NAO in the future climate projections than in the historical period, the influence of this climate mode on CEUR climate may be seen as potentially reduced.

\section{Conclusions}

In this study, an RCM single-model initial-condition large ensemble is analyzed with a special focus on the downscaled 
responses to a teleconnection, the NAO, that is present in the driving data. For proper assessment, the driving GCM ensemble is also included in the study. With regard to the key questions raised in the introduction, the following can be stated:

a. The ClimEx RCM-LE and its driving GCM-LE are able to depict a robust NAO pattern under current forcing conditions. Each member represents a distinct climate evolution while sharing comparable statistics with all other 49 realizations and producing NAO and response patterns that are more robust than patterns of individual realizations. The ensemble also shows climate statistics that are comparable with the reference time series and patterns. The clearly visible connection of the NAO with nSAT mean and PR sum follows well-known patterns and allows to derive robust information on the influence of the NAO on nSAT variability (nSAT SD).

b. The RCM is able to reproduce the large-scale SLP pattern and realistic response patterns in the analyzed domain. Clearly more topographic features are visible in CRCM5-LE than in CanESM2-LE, which suggests added value by the RCM regarding the evaluation of small-scale NAO impacts. Deviations of nSAT and PR responses between members vary spatially within the domain and are found mostly in regions with strongest NAO responses.

c. Internal variability of the NAO pattern is expressed very well within the 50-member single-model ensembles and easily spans the observations regarding various indicators. The range of NAO responses is represented consistently between the driving GCM and the nested RCM. The spread is shifted towards stronger NAO-nSAT/PR relations in the RCM compared with the GCM in both time horizons. d. Concerning climate change, several changes go hand in hand: the winter index variability is reduced, the overall winter variability of nSAT and PR and also the fraction of NAO-explained nSAT is reduced, the relationship between NAO and response variables is weakened, and the covariability of CanESM2 and CRCM5 subset regions for all variables is reduced.

While these results are especially valid for the analyzed GCM-RCM combination, they allow drawing some general conclusions. The results strengthen the validity of this GCM-RCM combination for further applications, as important large-scale teleconnections only present in the GCM propagate properly to the fine-scale dynamics in the RCM. The RCM does not alter the spread of driving GCM data which is valuable information for impact modeling with a focus on internal variability. The results also stress the importance of single-model ensembles for evaluating and estimating internal variability since single realizations show considerable variations among themselves and also deviations from the ensemble mean. So the ensemble mean and the ensemble spread together are needed for robust assessment of climate modes and whether a given model is able to reproduce the phenomenon of interest. 


\section{Appendix A}

(a) CRCM5 error tas

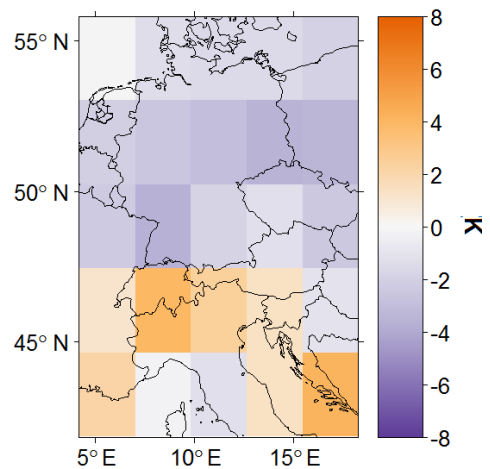

(d) CRCM5 error $\mathrm{pr}$

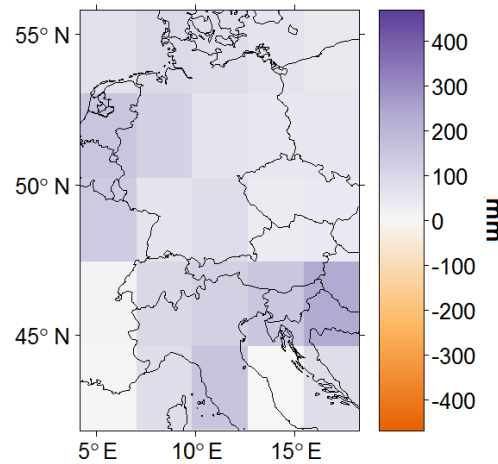

(b) CanESM2 error tas

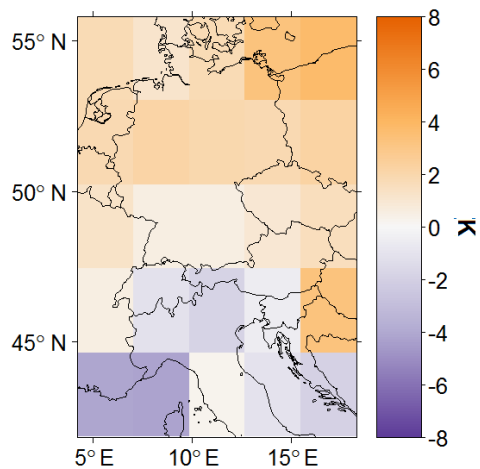

(e) CanESM2 error $\mathrm{pr}$

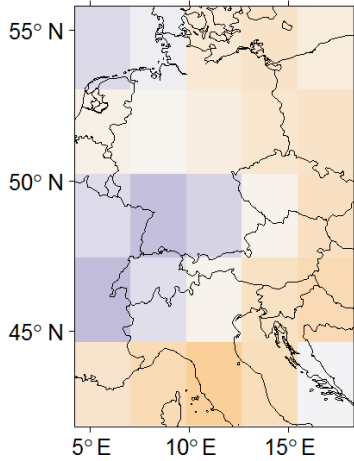

(c) CRCM5 error (member) tas

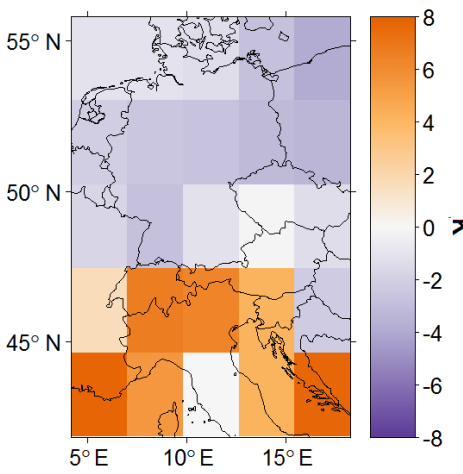

(f) CRCM5 error (member) pr

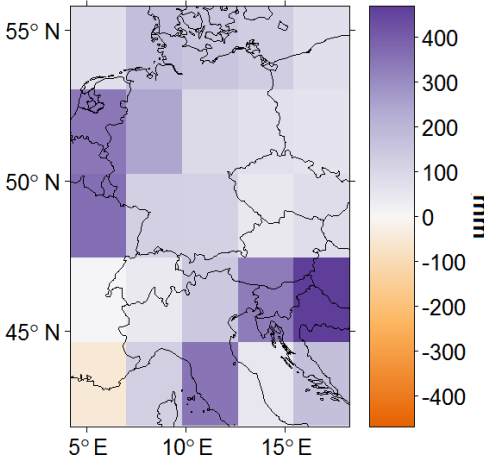

Figure A1. Model deviation for the 1981-2010 winter mean nSAT mean (a-c) and winter mean PR sum (d-f) in GCM resolution (2.8 $8^{\circ}$. (a, d) Error of CRCM5 under ERA-I boundary conditions (difference between CRCM5/ERA-I and ERA-I). (b, e) Error of CanESM2-LE towards ERA-I data (ensemble mean of differences between CanESM2-LE members and ERA-I). (c, f) CRCM5 error under CanESM2-LE boundary conditions (ensemble mean of differences between CRCM5 members and corresponding CanESM2 members). 
(a) ERA-I 1981-2010

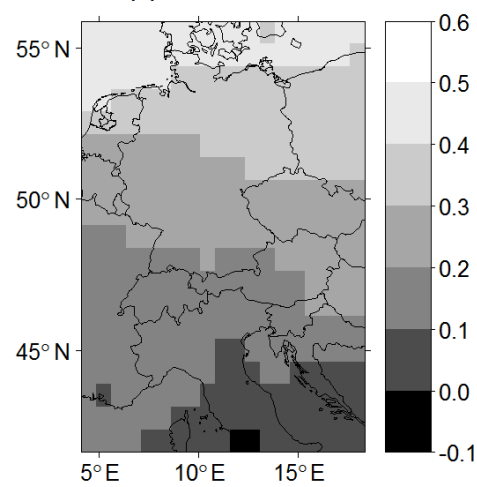

(d) CRCM5/ERA-I 1981-2010

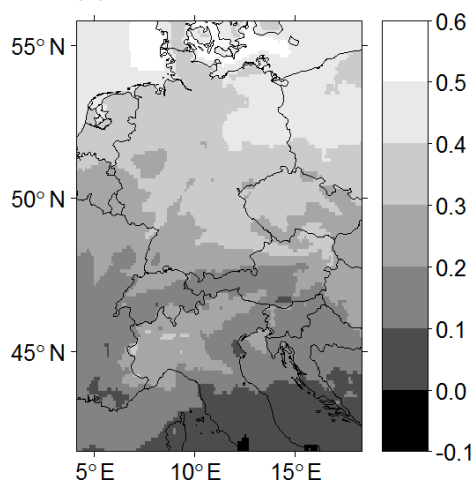

(b) CanESM2-LE 1981-2010

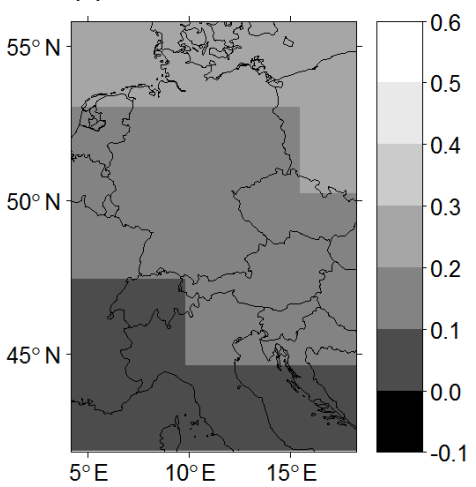

(e) CRCM5-LE 1981-2010

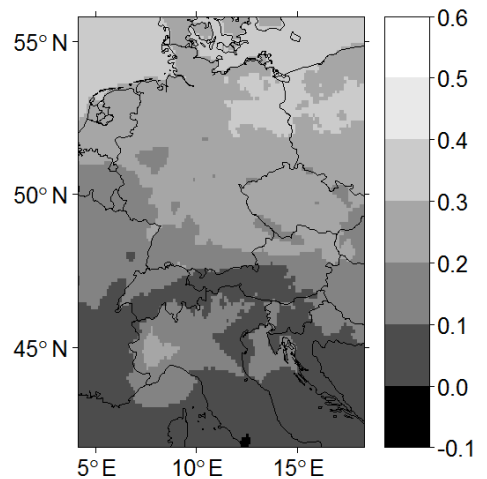

(c) CanESM2-LE 2070-2099

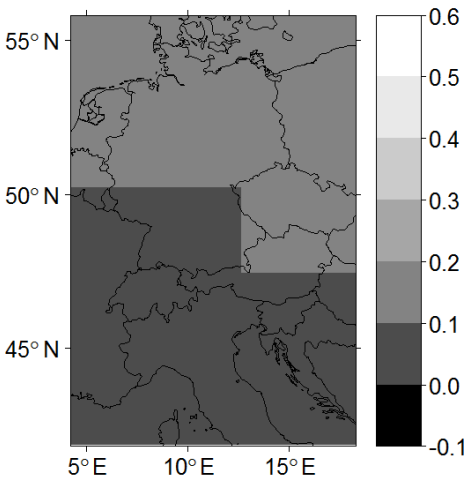

(f) CRCM5-LE 2070-2099

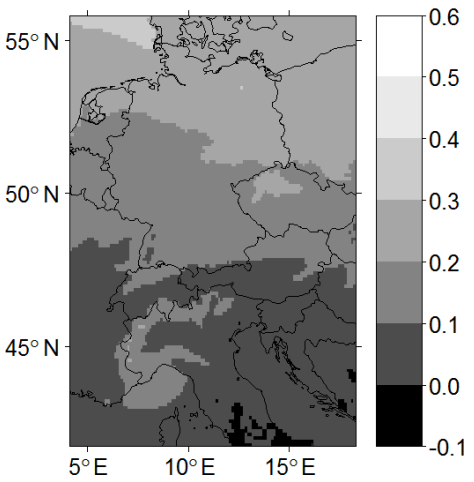

Figure A2. Ratio of nSAT $\alpha_{1}$ and winter mean daily standard deviation of nSAT for driving data (a-c) and RCM data (d-f) during historical $(\mathbf{a}, \mathbf{b}, \mathbf{d}, \mathbf{e})$ and future $(\mathbf{c}, \mathbf{f})$ conditions. The panels show the proportion of nSAT $\alpha_{1}$ in winter mean daily standard deviation of nSAT. 

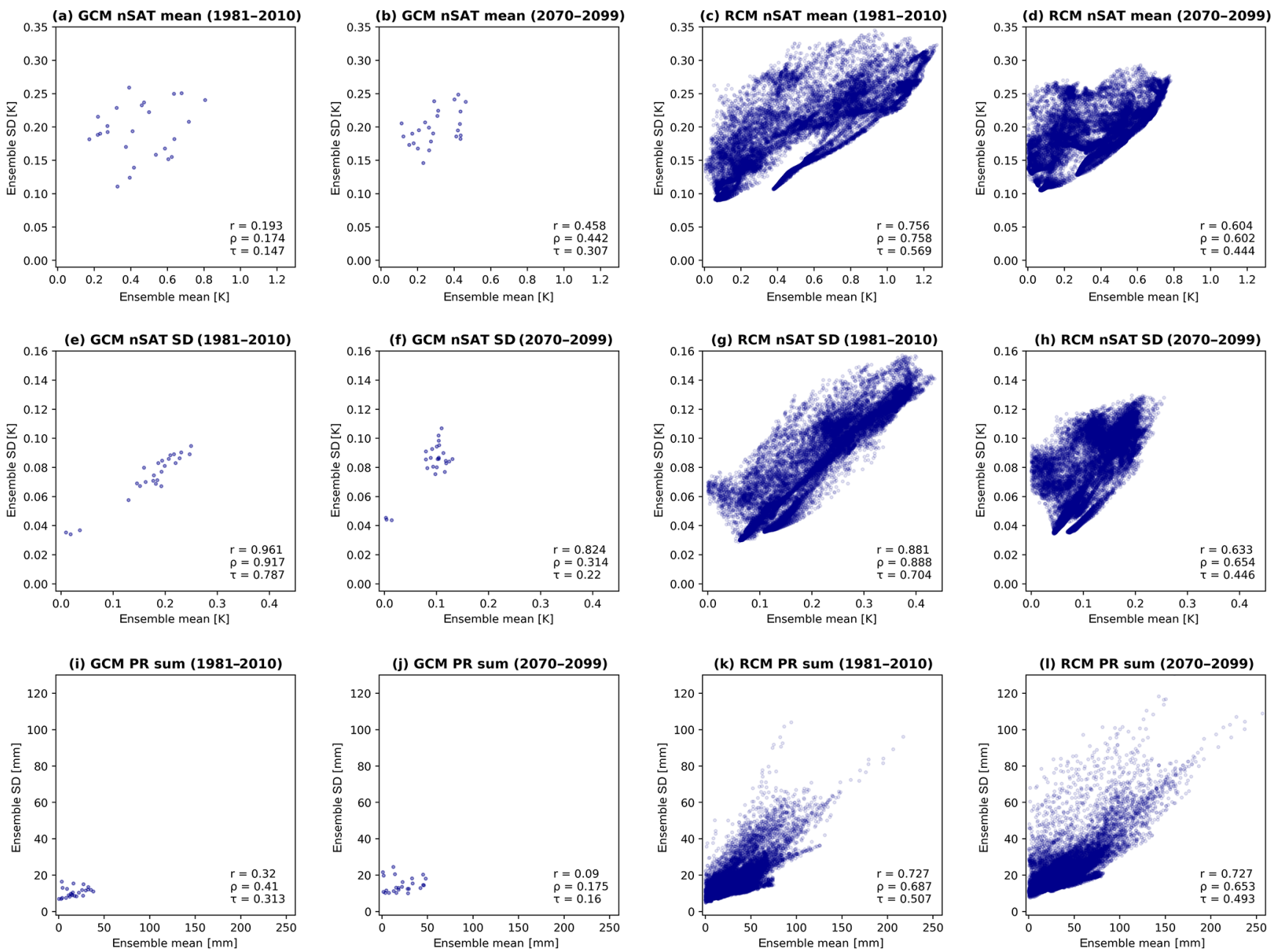

Figure A3. Relationship between LE mean and SD values of CanESM2-LE (GCM) and CRCM5-LE (RCM) for variables nSAT mean (a-d), nSAT SD (e-h), PR sum (i-l) for hist and fut periods. Lower right corner: $r$ - Pearson correlation coefficient, $\rho-$ Spearman rank correlation coefficient, $\tau-$ Kendall's tau. 
(a) nSAT mean NAO+

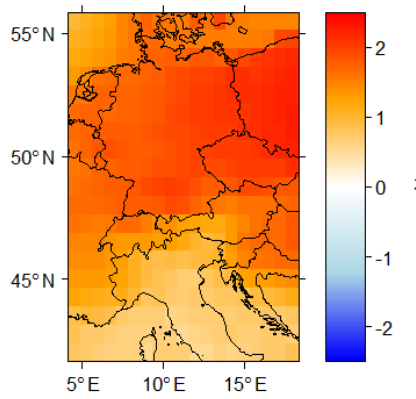

(e) nSAT mean NAO+ (SD)
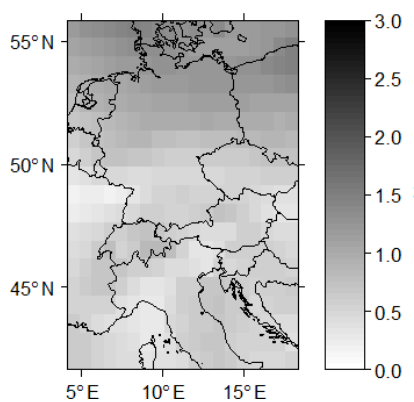

(b) nSAT mean NAO-

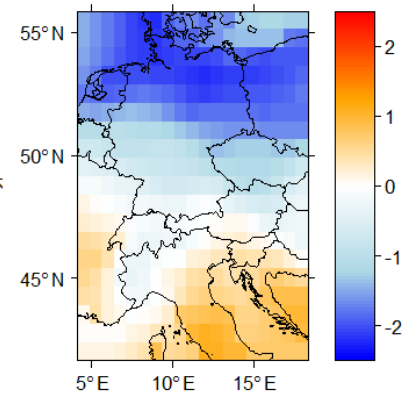

(f) nSAT mean NAO- (SD)

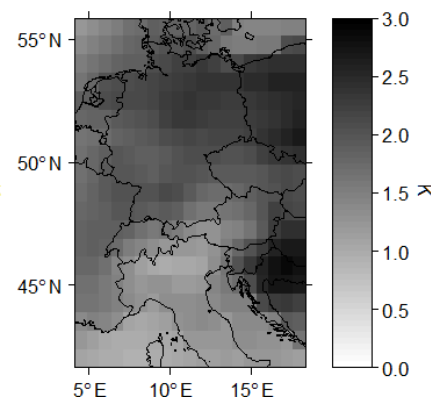

(c) PR sum NAO+

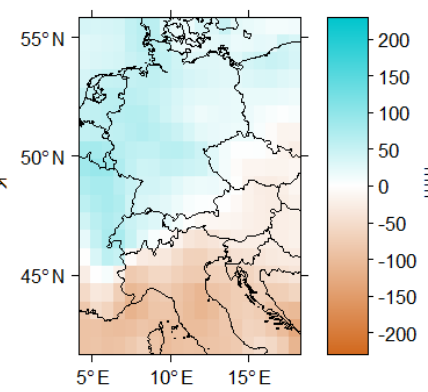

(g) PR sum NAO+ (SD)

(d) PR sum NAO-

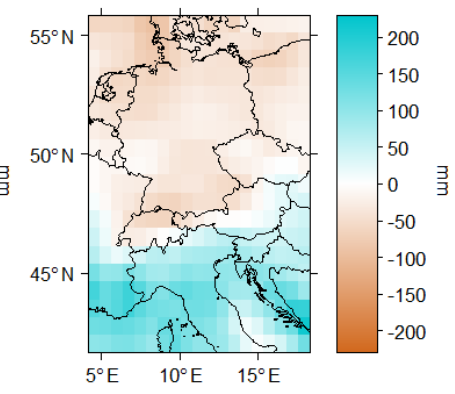

(h) PR sum NAO- (SD)

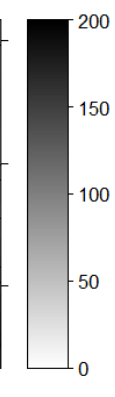

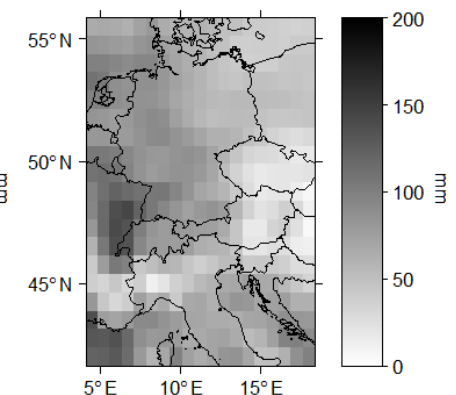

Figure A4. ERA-I anomalies from the long-term mean of nSAT mean in K and PR sum in mm in NAO positive $(1989,1990,1994,1995)$ and negative $(1996,2001,2010)$ winters. Mean index value for positive (negative) NAO phases is $+1.498(-2.103)$. 
Data availability. Ensemble model data used in this study may be retrieved from the following sources: CanESM2LE data are available via https://open.canada.ca/data/en/dataset/ aa7b6823-fd1e-49ff-a6fb-68076a4a477c (Environment and Climate Change Canada, 2020). CRCM5-LE data can be retrieved at https://climex-data.srv.lrz.de/Public/ (Ouranos, 2020). The ERAInterim reanalysis data set was obtained at https://apps.ecmwf.int/ datasets/data/interim-full-daily/levtype $=\mathrm{sfc} /$ (European Centre for Medium-Range Weather Forecasts, 2020).

Author contributions. This study was conceptualized by AB under supervision of RL. Formal analysis, visualization of results and writing of the original draft was performed by AB. All authors contributed to the interpretation of the findings and revision of the paper.

Competing interests. The authors declare that they have no conflict of interest.

Special issue statement. This article is part of the special issue "Large Ensemble Climate Model Simulations: Exploring Natural Variability, Change Signals and Impacts". It is not associated with a conference.

Acknowledgements. The authors would like to thank two anonymous reviewers for their valuable input which helped to considerably improve this work. This research was conducted within the ClimEx project. CRCM5 was developed by the ESCER Centre of Université du Québec à Montréal (UQAM; https://escer.uqam.ca/, last access: 7 July 2020) in collaboration with Environment and Climate Change Canada. We acknowledge Environment and Climate Change Canada's Canadian Centre for Climate Modelling and Analysis for executing and making available the CanESM2 Large Ensemble simulations used in this study, and the Canadian Sea Ice and Snow Evolution Network for proposing the simulations. Computations with CRCM5 for the ClimEx project were made on the SuperMUC supercomputer at the Leibniz Supercomputing Centre (LRZ) of the Bavarian Academy of Sciences and Humanities. The operation of this supercomputer is funded via the Gauss Centre for Supercomputing (GCS) by the German Federal Ministry of Education and Research and the Bavarian State Ministry of Education, Science and the Arts.

Financial support. The ClimEx project has been supported by the Bavarian State Ministry for the Environment and Consumer Protection (grant no. 81-0270-024570/2015).

Review statement. This paper was edited by Sebastian Milinski and reviewed by two anonymous referees.

\section{References}

Aalbers, E. E., Lenderink, G., van Meijgaard, E., and van den Hurk, B. J. J. M.: Local-scale changes in mean and heavy precipitation in Western Europe, climate change or internal variability?, Clim. Dynam., 50, 4745-4766, https://doi.org/10.1007/s00382017-3901-9, 2018.

Andrews, M. B., Knight, J. R., and Gray, L. J.: A simulated lagged response of the North Atlantic Oscillation to the solar cycle over the period 1960-2009, Environ. Res. Lett., 10, 054022, https://doi.org/10.1088/1748-9326/10/5/054022, 2015.

Benedict, J. J., Lee, S., and Feldstein, S. B.: Synoptic View of the North Atlantic Oscillation, J. Atmos. Sci., 61, 121-144, https://doi.org/10.1175/15200469(2004)061<0121:SVOTNA>2.0.CO;2, 2004.

Cattiaux, J., Douville, H., and Peings, Y.: European temperatures in CMIP5: origins of present-day biases and future uncertainties, Clim. Dynam., 41, 2889-2907, https://doi.org/10.1007/s00382013-1731-y, 2013.

Christensen, J. H., Krishna Kumar, K., Aldrian, E., An, S.-I., Cavalcanti, I. F. A., de Castro, M., Dong, W., Goswami, P., Hall, A., Kanyanga, J. K., Kitoh, A., Kossin, J., Lau, N.-C. and Renwick, J. and Stephenson, D. B. and Xie, S.-P., and Zhou, T: Climate Phenomena and their Relevance for Future Regional Climate Change, in: Climate Change 2013: The Physical Science Basis. Contribution of Working Group I to the Fifth Assessment Report of the Intergovernmental Panel on Climate Change, edited by: Stocker, T. F., Qin, D., Plattner, G.-K., Tignor, M., Allen, S. K., Boschung, J., Nauels, A., Xia, Y., Bex, V., and Midgley, P. M., Cambridge University Press, Cambridge, UK and New York, USA, 1271-1308, 2013.

Comas-Bru, L. and McDermott, F.: Impacts of the EA and SCA patterns on the European twentieth century NAO-winter climate relationship, Q. J. Roy. Meteorol. Soc., 140, 354-363, https://doi.org/10.1002/qj.2158, 2014.

Cropper, T., Hanna, E., Valente, M. A., and Jónsson, T.: A daily Azores-Iceland North Atlantic Oscillation index back to 1850 , Geosci. Data J., 2, 12-24, https://doi.org/10.1002/gdj3.23, 2015.

Dee, D. P., Uppala, S. M., Simmons, A. J., Berrisford, P., Poli, P., Kobayashi, S., Andrae, U., Balmaseda, M. A., Balsamo, G., Bauer, P., Bechtold, P., Beljaars, A. C. M., van de Berg, L., Bidlot, J., Bormann, N., Delsol, C., Dragani, R., Fuentes, M., Geer, A. J., Haimberger, L., Healy, S. B., Hersbach, H., Hólm, E. V., Isaksen, L., Kållberg, P., Köhler, M., Matricardi, M., McNally, A. P., Monge-Sanz, B. M., Morcrette, J.-J., Park, B.-K., Peubey, C., de Rosnay, P., Tavolato, C., Thépaut, J.-N., and Vitart, F.: The ERA-Interim reanalysis: configuration and performance of the data assimilation system, Q. J. Roy. Meteorol. Soc., 137, 553597, https://doi.org/10.1002/qj.828, 2011.

Delworth, T. L., Zeng, F., Vecchi, G. A., Yang, X., Zhang, L., and Zhang, R.: The North Atlantic Oscillation as a driver of rapid climate change in the Northern Hemisphere, Nat. Geosci., 9, 509512, https://doi.org/10.1038/ngeo2738, 2016.

Déqué, M., Rowell, D. P., Lüthi, D., Giorgi, F., Christensen, J. H., Rockel, B., Jacob, D., Kjellström, E., de Castro, M., and van den Hurk, B.: An intercomparison of regional climate simulations for Europe: assessing uncertainties in model projections, Climatic Change, 81, 53-70, https://doi.org/10.1007/s10584-006-9228-x, 2007. 
Deser, C., Phillips, A., Bourdette, V., and Teng, H.: Uncertainty in climate change projections: the role of internal variability, Clim. Dynam., 38, 527-546, https://doi.org/10.1007/s00382010-0977-x, 2012.

Deser, C., Hurrell, J. W., and Phillips, A. S.: The role of the North Atlantic Oscillation in European climate projections, Clim. Dynam., 49, 3141-3157, https://doi.org/10.1007/s00382-016-3502z, 2017.

Environment and Climate Change Canada: CanESM2 Large Ensembles Output, available at: https://open.canada.ca/data/ en/dataset/aa7b6823-fd1e-49ff-a6fb-68076a4a477c, last access: 3 July 2020.

European Centre for Medium-Range Weather Forecasts: ERAInterim, available at: https://apps.ecmwf.int/datasets/data/ interim-full-daily/levtype $=$ sfc/, last access: 3 July 2020.

Frankcombe, L. M., England, M. H., Mann, M. E., and Steinman, B. A.: Separating Internal Variability from the Externally Forced Climate Response, J. Climate, 28, 8184-8202, https://doi.org/10.1175/JCLI-D-15-0069.1, 2015.

Fyfe, J. C., Derksen, C., Mudryk, L., Flato, G. M., Santer, B. D., Swart, N. C., Molotch, N. P., Zhang, X., Wan, H., Arora, V. K., Scinocca, J., and Jiao, Y.: Large near-term projected snowpack loss over the western United States, Nat. Commun., 8, 14996, https://doi.org/10.1038/ncomms14996, 2017.

Gillett, N. P. and Fyfe, J. C.: Annular mode changes in the CMIP5 simulations, Geophys. Res. Lett., 40, 1189-1193, https://doi.org/10.1002/grl.50249, 2013.

Giorgi, F., Jones, C., and Asrar, G. R.: Addressing climate information needs at the regional level: the CORDEX framework, WMO Bull., 58, 175-183, 2009.

Hanna, E., Cropper, T. E., Jones, P. D., Scaife, A. A., and Allan, $\mathrm{R}$ : Recent seasonal asymmetric changes in the NAO (a marked summer decline and increased winter variability) and associated changes in the AO and Greenland Blocking Index, Int. J. Climatol., 35, 2540-2554, https://doi.org/10.1002/joc.4157, 2015.

Hansen, F., Greatbatch, R. J., Gollan, G., Jung, T., and Weisheimer, A.: Remote control of North Atlantic Oscillation predictability via the stratosphere, Q. J. Roy. Meteorol. Soc., 143, 706-719, https://doi.org/10.1002/qj.2958, 2017.

Hawkins, E. and Sutton, R.: The Potential to Narrow Uncertainty in Regional Climate Predictions, B. Am. Meteorol. Soc., 90, 10951108, https://doi.org/10.1175/2009BAMS2607.1, 2009.

Hawkins, E. and Sutton, R.: The potential to narrow uncertainty in projections of regional precipitation change, Clim. Dynam., 37, 407-418, https://doi.org/10.1007/s00382-010-0810-6, 2011.

Hurrell, J. W.: Decadal Trends in the North Atlantic Oscillation: Regional Temperatures and Precipitation, Science, 269, 676-679, https://doi.org/10.1126/science.269.5224.676, 1995.

Hurrell, J. W. and Deser, C.: North Atlantic climate variability: The role of the North Atlantic Oscillation, J. Mar. Syst., 79, 231-244 https://doi.org/10.1016/j.jmarsys.2009.11.002, 2010.

Hurrell, J. W. and Van Loon, H.: Decadal variations in climate associated with the North Atlantic Oscillation, Climatic Change, 36, 301-326, https://doi.org/10.1023/A:1005314315270, 1997.

Iles, C. and Hegerl, G.: Role of the North Atlantic Oscillation in decadal temperature trends, Environ. Res. Lett., 12, 114010, https://doi.org/10.1088/1748-9326/aa9152, 2017.

Jones, P. D., Osborn, T. J., and Briffa, K. R.: Pressure-Based Measures of the North Atlantic Oscillation (NAO): A Comparison and an Assessment of Changes in the Strength of the NAO and its Influence on Surface Climate Parameters, in: The North Atlantic Oscillation: Climatic Significance and Environmental Impact, edited by: Hurrell, J. W., Kushnir, Y., Ottersen, G., and Visbeck, M., AGU - American Geophysical Union, Washington, D.C., 51-62, 2013.

Kay, J. E., Deser, C., Phillips, A., Mai, A., Hannay, C., Strand, G., Arblaster, J. M., Bates, S. C., Danabasoglu, G., Edwards, J., Holland, M., Kushner, P., Lamarque, J.-F., Lawrence, D., Lindsay, K., Middleton, A., Munoz, E., Neale, R., Oleson, K., Polvani, L., and Vertenstein, M.: The Community Earth System Model (CESM) Large Ensemble Project: A Community Resource for Studying Climate Change in the Presence of Internal Climate Variability, B. Am. Meteorol. Soc., 96, 1333-1349, https://doi.org/10.1175/BAMS-D-13-00255.1, 2015.

Kirchmeier-Young, M. C., Zwiers, F. W., and Gillett, N. P.: Attribution of Extreme Events in Arctic Sea Ice Extent, J. Climate, 30, 553-571, https://doi.org/10.1175/JCLI-D-16-0412.1, 2017.

Kirtman, B., Power, S. B., Adedoyin, J. A., Boer, G. J., Bojariu, R., Camilloni, I., Doblas-Reyes, F. J., Fiore, A. M., Kimoto, M., Meehl, G. A., Prather, M., Sarr, A., Schär, C., Sutton, R., van Oldenborgh, G. J., Vecchi, G., and Wang, H. J.: Nearterm Climate Change: Projections and Predictability, in: Climate Change 2013: The Physical Science Basis. Contribution of Working Group I to the Fifth Assessment Report of the Intergovernmental Panel on Climate Change, edited by: Stocker, T. F., Qin, D., Plattner, G.-K., Tignor, M., Allen, S. K., Boschung, J., Nauels, A., Xia, Y., Bex, V., and Midgley, P. M., Cambridge University Press, Cambridge, UK and New York, USA, 953-1028, 2013.

Kushner, P. J., Mudryk, L. R., Merryfield, W., Ambadan, J. T., Berg, A., Bichet, A., Brown, R., Derksen, C., Déry, S. J., Dirkson, A., Flato, G., Fletcher, C. G., Fyfe, J. C., Gillett, N., Haas, C., Howell, S., Laliberté, F., McCusker, K., Sigmond, M., SospedraAlfonso, R., Tandon, N. F., Thackeray, C., Tremblay, B., and Zwiers, F. W.: Canadian snow and sea ice: assessment of snow, sea ice, and related climate processes in Canada's Earth system model and climate-prediction system, The Cryosphere, 12, 1137-1156, https://doi.org/10.5194/tc-12-1137-2018, 2018.

Leduc, M. and Laprise, R.: Regional climate model sensitivity to domain size, Clim. Dynam., 32, 833-854, https://doi.org/10.1007/s00382-008-0400-z, 2009.

Leduc, M., Mailhot, A., Frigon, A., Martel, J.-L., Ludwig, R., Brietzke, G. B., Giguère, M., Brissette, F., Turcotte, R., Braun, M., and Scinocca, J.: The ClimEx Project: A 50-Member Ensemble of Climate Change Projections at 12-km Resolution over Europe and Northeastern North America with the Canadian Regional Climate Model (CRCM5), J. Appl. Meteorol. Clim., 58, 663693, https://doi.org/10.1175/JAMC-D-18-0021.1, 2019.

Maher, N., Matei, D., Milinski, S., and Marotzke, J.: ENSO Change in Climate Projections: Forced Response or Internal Variability?, Geophys. Res. Lett., 45, 11390-11398, https://doi.org/10.1029/2018GL079764, 2018.

Maher, N., Milinski, S., Suarez-Gutierrez, L., Botzet, M., Dobrynin, M., Kornblueh, L., Kröger, J., Takano, Y., Ghosh, R., Hedemann, C., Li, C., Li, H., Manzini, E., Notz, D., Putrasahan, D., Boysen, L., Claussen, M., Ilyina, T., Olonscheck, D., Raddatz, T., Stevens, B., and Marotzke, J.: The Max Planck Institute Grand Ensemble: Enabling the Exploration of Climate 
System Variability, J. Adv. Model. Earth Syst., 11, 2050-2069, https://doi.org/10.1029/2019MS001639, 2019.

Moore, G. W. K., Renfrew, I. A., and Pickart, R. S.: Multidecadal Mobility of the North Atlantic Oscillation, J. Climate, 26, 24532466, https://doi.org/10.1175/JCLI-D-12-00023.1, 2013.

Osborn, T. J.: Simulating the winter North Atlantic Oscillation: the roles of internal variability and greenhouse gas forcing, Clim. Dynam., 22, 605-623, https://doi.org/10.1007/s00382004-0405-1, 2004.

Ouranos: CRCM5-LE ClimEx, available at: https://climex-data.srv. lrz.de/Public/, last access: 3 July 2020.

Pokorná, L. and Huth, R.: Climate impacts of the NAO are sensitive to how the NAO is defined, Theor. Appl. Climatol., 119, 639652, https://doi.org/10.1007/s00704-014-1116-0, 2015.

Reintges, A., Latif, M., and Park, W.: Sub-decadal North Atlantic Oscillation variability in observations and the Kiel Climate Model, Clim. Dynam., 48, 3475-3487, https://doi.org/10.1007/s00382-016-3279-0, 2017.

Rogers, J. C.: The Association between the North Atlantic Oscillation and the Southern Oscillation in the Northern Hemisphere, Mon. Weather Rev., 112, 1999-2015, https://doi.org/10.1175/15200493(1984)112<1999:TABTNA>2.0.CO;2, 1984.

Ruprich-Robert, Y. and Cassou, C.: Combined influences of seasonal East Atlantic Pattern and North Atlantic Oscillation to excite Atlantic multidecadal variability in a climate model, Clim. Dynam., 44, 229-253, https://doi.org/10.1007/s00382014-2176-7, 2015.

Schulzweida, U.: CDO User Guide, Climate Data Operators Version 1.9.1, October 2017, MPI for Meteorology, available at: https://code.mpimet.mpg.de/projects/cdo/embedded/cdo.pdf (last access: 1 April 2018), 2017.

Screen, J. A.: The missing Northern European winter cooling response to Arctic sea ice loss, Nat. Commun., 8, 14603, https://doi.org/10.1038/ncomms14603, 2017.

Stephenson, D. B., Pavan, V., Collins, M., Junge, M. M., and Quadrelli, R., and Participating CMIP2 Modelling Groups: North Atlantic Oscillation response to transient greenhouse gas forcing and the impact on European winter climate: a CMIP2 multi-model assessment, Clim. Dynam., 27, 401-420, https://doi.org/10.1007/s00382-006-0140-x, 2006.

Ulbrich, U. and Christoph, M.: A shift of the NAO and increasing storm track activity over Europe due to anthropogenic greenhouse gas forcing, Clim. Dynam., 15, 551-559, https://doi.org/10.1007/s003820050299, 1999.
Ulbrich, U., Pinto, J. G., Kupfer, H., Leckebusch, G. C., Spangehl, T., and Reyers, M.: Changing Northern Hemisphere Storm Tracks in an Ensemble of IPCC Climate Change Simulations, J. Climate, 21, 1669-1679, https://doi.org/10.1175/2007JCLI1992.1, 2008.

von Storch, H. and Zwiers, F. W.: Statistical Analysis in Climate Research, Cambridge University Press, Cambridge, 2003.

von Trentini, F., Leduc, M., and Ludwig, R.: Assessing natural variability in RCM signals: comparison of a multi model EURO-CORDEX ensemble with a 50-member single model large ensemble, Clim. Dynam., 53, 1963-1979, https://doi.org/10.1007/s00382-019-04755-8, 2019.

Warner, J. L.: Arctic sea ice - a driver of the winter NAO?, Weather, 73, 307-310, https://doi.org/10.1002/wea.3399, 2018.

Wilks, D. S.: "The Stippling Shows Statistically Significant Grid Points": How Research Results are Routinely Overstated and Overinterpreted, and What to Do about It, B. Am. Meteorol. Soc., 97, 2263-2273, https://doi.org/10.1175/BAMS-D-15$00267.1,2016$.

Woollings, T., Franzke, C., Hodson, D. L. R., Dong, B., Barnes, E. A., Raible, C. C., and Pinto, J. G.: A Regime View of the North Atlantic Oscillation and Its Response to Anthropogenic Forcing, J. Climate, 23, 1291-1307, https://doi.org/10.1175/2009JCLI3087.1, 2010.

Woollings, T., Franzke, C., Hodson, D., Dong, B., Barnes, E., Raible, C., and Pinto, J.: Contrasting interannual and multidecadal NAO variability, Clim. Dynam., 45, 539-556, https://doi.org/10.1007/s00382-014-2237-y, 2015.

Xu, T., Shi, Z., Wang, H., and An, Z.: Nonstationary impact of the winter North Atlantic Oscillation and the response of midlatitude Eurasian climate, Theor. Appl. Climatol., 124, 1-14, https://doi.org/10.1007/s00704-015-1396-z, 2016.

Zwiers, F. W. and von Storch, H.: On the role of statistics in climate research, Int. J. Climatol., 24, 665-680, https://doi.org/10.1002/joc.1027, 2004. 